Article

\title{
Fuel Cell Characteristic Curve Approximation Using the Bézier Curve Technique
}

\author{
Mohamed Louzazni ${ }^{1, *(D)}$, Sameer Al-Dahidi ${ }^{2}$ (D) and Marco Mussetta ${ }^{3, *(D)}$ \\ 1 National School of Applied Sciences, Abdelmalek Essaadi University, Tetouan B.P. 2117, Morocco \\ 2 Mechanical and Maintenance Engineering Department, School of Applied Technical Sciences, \\ German Jordanian University, Amman 11180, Jordan; sameer.aldahidi@gju.edu.jo \\ 3 Dipartimento di Energia, Politecnico di Milano, Via Lambruschini 4, 20156 Milano, Italy \\ * Correspondence: louzazni@msn.com (M.L.); marco.mussetta@polimi.it (M.M.)
}

Received: 31 July 2020; Accepted: 29 September 2020; Published: 1 October 2020

\begin{abstract}
Accurate modelling of the fuel cell characteristics curve is essential for the simulation analysis, control management, performance evaluation, and fault detection of fuel cell power systems. However, the big challenge in fuel cell modelling is the multi-variable complexity of the characteristic curves. In this paper, we propose the implementation of a computer graphic technique called Bézier curve to approximate the characteristics curves of the fuel cell. Four different case studies are examined as follows: Ballard Systems, Horizon H-12 W stack, NedStackPS6, and 250 W proton exchange membrane fuel cells (PEMFC). The main objective is to minimize the absolute errors between experimental and calculated data by using the control points of the Bernstein-Bézier function and de Casteljau's algorithm. The application of this technique entails subdividing the fuel cell curve to some segments, where each segment is approximated by a Bézier curve so that the approximation error is minimized. Further, the performance and accuracy of the proposed techniques are compared with recent results obtained by different metaheuristic algorithms and analytical methods. The comparison is carried out in terms of various statistical error indicators, such as Individual Absolute Error (IAE), Relative Error (RE), Root Mean Square Error (RMSE), Mean Bias Errors (MBE), and Autocorrelation Function $(A C F)$. The results obtained by the Bézier curve technique show an excellent agreement with experimental data and are more accurate than those obtained by other comparative techniques.
\end{abstract}

Keywords: fuel cell; characteristics curve; computer graphic technique; approximation; Bézier curve

\section{Introduction}

Recently, the fuel cell (FC) has been recognized by scientists and industrialists as a significant renewable energy source. Specialists considers it as the lowest impact and the least of all the major problems facing the global energy system [1]. It consist essentially of two electrodes viz., a cathode, anode and a Proton Exchange Membrane (PEM) between them as an electrolyte. The two electrodes are in contact with bipolar plates embedding gas flow channels within which the reactive gasses $\left(\mathrm{H}_{2}\right.$ and $\mathrm{O}_{2}$ ) are delivered to the device. It generates electricity as long as the fuel is delivered in the form of hydrogen. The FC is a type of sustainable energy that converts the chemical process between hydrogen and oxygen to electrical energy. The use of the fuel cell is due to its advantages over other renewable energy sources, e.g., the electrical efficacies of FC range between $50 \%$ and $70 \%$, rich reserves, high utilization efficiency, versatility, high safety, and flexibility in the use of the necessary fuels. Thus, it has become a genuinely competitive power source of energy [2,3]. Generally, two types of fuel can be distinguished in industries; they are: (i) Proton Exchange Membrane FCs (PEMFCs) and Solid-Oxide FCs (SOFCs). PEMFC is one type of fuel cell technology in which high power density and compactness work at low temperature $\left(-20^{\circ} \mathrm{C}\right.$ to $\left.-100{ }^{\circ} \mathrm{C}\right)$. In the solid oxide fuel cell (SOFC), solid oxide material is 
used as an electrolyte and is ideal for energy production and hybrid electric implementations, because they have higher temperature levels $\left(600^{\circ} \mathrm{C}\right.$ to $\left.700{ }^{\circ} \mathrm{C}\right)$ and higher efficiency [4]. Standard electrolyte materials in SOFCs contain zirconia, along with a small amount of yttrium doping, samarium doped ceria, or gadolinium doped ceria $(8 \mathrm{~mol} \%)$. The main problems and challenges in PEMFCs research occur in the catalyst layers (CLs) since they are complex and heterogeneous [5]. The catalyst layers need to be constructed to produce high amounts of desirable reactions and reduce the amount of catalyst needed to obtain the required levels of power production. In order to achieve the objective, the aforementioned criteria must be considered: (i) strong three-phase interface in the CL, (ii) effective transfer of protons, (iii) fast transfer of reactant and liquid gasses, and elimination of condensed water, and (iv) continuous electronic current passage between the reaction sites and the current collector. The overall efficiency of the CLs depends on all these important factors, and it is therefore necessary for the identification of electrode structures and operating conditions [6]. On the other hand, PEMFCs are used in mobile cell phones, portable music players, and electric and space vehicles due to high power capacity, potential cost reduction, relatively low operating temperature $\left(60^{\circ} \mathrm{C}\right.$ to $\left.100{ }^{\circ} \mathrm{C}\right)$, broad application prospect, zero or very low emissions, low noise, low corrosion rate, no waste generation, solid electrolytes, and electrical efficiency of about 50\% $[7,8]$. PEMFCs have some limitations, such as weak oxygen reduction kinetics, weak water and heat regulation, CO toxicity, gas diffusion layer, flow field layers and degradation. Further, manufacturing of the FC is expensive due to the high cost of catalysts, the hydrogen is costly to manufacture and not easily accessible and there is a lack of infrastructure to support the distribution of hydrogen [9]. The degradation rates are considered from the major disadvantage due to the presence of liquid water in the stack system. By converting to the high-temperature process, this is minimized since there is no liquid water present in the stack.

Over the last decade, and due to the revolution in FC technologies, numerous researchers have paid particular attention to modeling, controlling, and parameter extractions [3]. The primary purpose of these studies is to develop an accurate FC model that can be correctly expressed in simulation studies and be very identical to experimental models. Meanwhile, modeling plays a vital role in the simulation, concept, configuration, analysis, and improvement of high-efficiency fuel cell systems. In order to understand and manage the functionality of the fuel cell, it is important to establish a stable model of the fuel cell [7]. The performance of the model depends mainly on reducing the error value between the simulation and the experimental results. Generally, the electrochemical model, based on mathematical formulations, is the most useful model for specialists to approximate the output characteristics of the FC system. Mathematical modelling is popularly used as a reasonable cost and an effective solution to experimental studies. Nonetheless, its efficacy is typically influenced by an inappropriate configuration of the parameters, such as stack temperature, the humidity of anode and cathode, gas pressure, and so on [10]. Recently, the most effective techniques are developing mathematical models [11] based on analytical models [12], empirical models [13] or semi-empirical models [14], and mechanistic models, and then the approximation of unidentified voltage-current (V-I) and power-voltage (P-I) curves through optimization techniques [15]. Within these models, the semi-empirical model established in [16], based on Nernst and Tafel equations, is widely recognized by the researchers. Due to the parametric equations of the FC model, it can be formulated as an optimization problem to approximate the FC curves and, thus, describe the behavior of characteristic curves.

Recently, numerous research papers have been focusing on developing different approaches to approximate the FC characteristic curves using analytical and meta-heuristic techniques, instead of using conventional analytical methods or meta-heuristic optimization algorithms, both in non-parameter [17] and parameter modelling [18]. Among the accepted empirical scientific methods, the electrochemical impedance spectrum method, combined with broadband current excitation [19], least square method adapted to fractional order models [20], semi-empirical model [21], generalized reduced gradient technique (GRG-1, GRG-2) [22], Gauss-Newton [23], Levenberg-Marquardt [23], and least square fitting [24]. However, such analytical methods are based on complex operations. These methods have 
some demerit points because they are based on mathematical manipulation, and the derivation imposes several restrictions, such as convexity, continuity, and differentiability, also, the approximations reduce the ultimate accuracy.

On the other hand, the meta-heuristic algorithms have prospered over the last few years, and have been effectively used to overcome several challenging optimization difficulties in specific various fields. In the literature, numerous meta-heuristic optimization techniques have been proposed to approximate the FC characteristic curves, including Shuffled Frog-Leaping Algorithm (SFLA), Firefly Optimization Algorithm (FOA), Imperialist Competitive Algorithm (ICA) [25], Shuffled Multi-Simplexes Search Algorithm (SMSA) [26], Hybrid Grey Wolf Optimization (HGWO) [27], Hybrid Vortex Search Algorithm and Differential Evolution [28], Eagle Strategy [8], Cuckoo Search Algorithm with Explosion Operator (CAEO) [29], Neural Network Optimizer (NNO) [30], Shark Smell Optimizer (SSO) [31], Slap Swarm Optimizer (SSO) [32], Grasshopper Optimization (GO) [33], Grey Wolf Optimizer (GWO) [34], Hybrid Teaching Learning Based Optimization-Differential Evolution [35], Hybrid Adaptive Differential Evolution Algorithm [36], Evolutionary Strategy [37], Genetic Algorithm (GA) and Manta Rays Foraging Optimizer (MRFO) [38], Transferred Adaptive Differential Evolution (TADE) [39], Adaptive Differential Evolution Algorithm (ADEA) [40], and Harmony Search Algorithm (HSA) [41]. In particular, these nature-inspired or artificial swarm intelligence have their own benefits and drawbacks, in which someone can overcome an unsolvable problem and not solve another one. Even so, the algorithms referenced are generally trapped at local optima and have large error values. Besides, the accuracy of such algorithms is strongly dependent on the selection of specific parameters, such as mutation probability, crossover probability, and the selection operator in the GA, as well as inertia weight, and social and cognitive parameters for particle swarm optimization. As a result, researchers are always looking for successful techniques capable of approximating the characteristics curves of the FC with low error and high accuracy.

As mentioned previously, most scientists have tried to improve the modeling of the FC, which requires a complex model with a degree of nonlinearity and multi-variability. The latter maintains that the FC characteristics curves are challenging to be tackled by using traditional methodologies to improve the effectiveness of V-I and P-I characteristic curves, and accurately reflect the ultimate performance. It is essential to define accurate curves using modern techniques properly. However, the critical requirement for choosing a method to approximate the FC characteristic curves is its precision. The primary needs for the techniques are accuracy, reliability, efficiency, detection limit, quantitation limit, flexibility, operating range, and robustness. An approximation technique with a low error is widely accepted as successful, and the calculated error is measured based on the discrepancy between the calculation and the experimental values.

For this reason, recently, several researchers have introduced the Computer Aided Geometric Design (CAGD) technique, Computer Graphics (CG), and Computer-Aided Design (CAD) to overcome all problems of the nonlinearity and complex functions to approximate curves and surfaces [42]. The Bézier curves technique is considered the most stable among all polynomial based on CAD and provides excellent representation for piecewise polynomial curves (since the Bézier curve has a continuous curvature, and can rapidly change the shape by adapting its control points and can be adjusted with an optimization algorithm) [43]. This technique is used to fit or approximated different geometry through different algorithms to minimize the distance between the experimental and control points. For example, Huo et al. [44] have applied the Bézier curve technique to approach and design the trajectory of the electric sail. A description of the thermal behavior of three-way mixing valves [45], estimation of the Kendall distribution function [46], and circle, and conic approximation [47,48], has been also carried out.

In this paper, an investigation and application of the control points of the Bernstein-Bézier technique for numerically approximating the V-I and P-I characteristics curve of FCs have been proposed. The main objective is to minimize the absolute errors between experimental and calculated data by using the control points of the Bernstein-Bézier technique. Four different case studies 
are examined as follows: PEMFC by M/S Ballard Systems, Horizon H-12 W stack, NedStack PS6 PEMFC stack, and $250 \mathrm{~W}$ PEMFC stack. To check the efficiency of the used technique and the performance of the obtained results, a statistical analysis is conducted to assess the precision and accuracy of the approximated V-I and P-I curves. The results obtained are compared to latest methods, such as the Whale Optimization Algorithm (WOA) [14], GRG-1 [22], GRG-2 [22], FOA [25], ICA [25], SFLA [25], SMSA [26], SSO [32], Modified Artificial Ecosystem Optimizatio (MAEO) [49], GA [38], MRFO [38], Grouping-based Global Harmony Search GGHS [50], Improved Harmouny Search (HIS) [50], Particle Swarm Optimization with adaptive inertia Weight (PSO-w) [50], and Chaotic Harris Hawks Optimization (CHHO) [51]. To evaluate the performance of the proposed method, various error parameters are computed, examined, and compared, such as Individual Absolute Error (IAE), Relative Error (RE), Root Mean Square Error (RMSE), Mean Bias Error (MBE), and Autocorrelation Function $(A C F)$. The obtained results are shown close to the experimental data, with a good agreement for most of the approximated curves. The proposed method outperforms the benchmark techniques from the literature.

The remaining of this article is structured as follows: Section 2 displays the mathematical model and fundamentals description of FCs. Section 3 presents the application of the Bézier curve technique to the FC curve. Section 4 depicts the evaluation of the statistical criteria. Sections 5 and 6 illustrate the obtained results and the analysis and discussion of the approximated curves, respectively. Lastly, conclusions and future works are drawn in Section 7.

\section{Fuel Cell Model}

A Fuel Cell (FC) is an electrical and chemical system that transforms chemical energy generally from hydrogen directly to electric power. The analogous electrical circuit may be used to simulate the complex behaviors of the FC and its polarization curves are depicted in Figure 1a,b, respectively [52]. This model is characterized by a sequence of equations and a set of parameters, the interpretation of which is crucial for successful simulation performance. The polarization is caused by chemical and physical factors associated with various elements in the fuel cell, such as temperature, pressure, and gas composition. The three primary types of polarization, named activation, ohmic (or resistance) and concentration, are illustrated in Figure $1 \mathrm{~b}$.

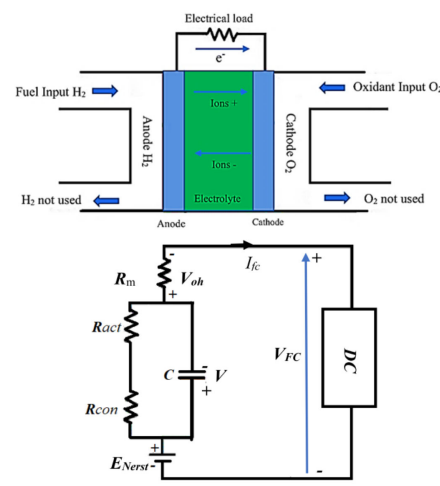

(a)

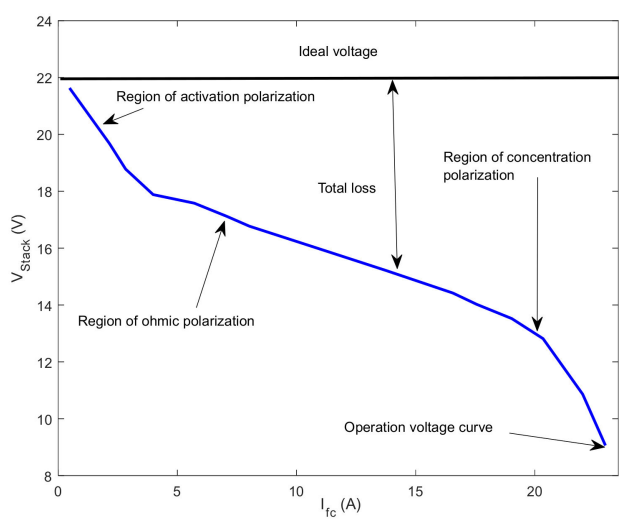

(b)

Figure 1. (a) Fundamental structure and electrical equivalent circuit of the FC, (b) voltage-current polarization curves of $250 \mathrm{~W}$ proton exchange membrane fuel cells (PEMFC) stack [53].

Moreover, the polarization voltage (or terminal voltage) of FC is given in function of thermodynamic voltage $E_{n e r n s t}$, activation voltage losses due to reaction kinetics $V_{a c t}$, the ohmic voltage losses from ionic and electronic resistance $V_{\text {ohm }}$, the concentration voltage losses due to mass transport $V_{c o n}$ and $n_{\text {cell }}$ is the number of cells. Generally, the real voltage output of a fuel cell could be 
written by starting with the thermodynamically predicted voltage and then subtracting the various overvoltage losses, as follow [16]:

$$
V_{\text {cell }}=n_{\text {cell }}\left(E_{\text {Nernst }}-V_{\text {act }}-V_{\text {ohmic }}-V_{\text {con }}\right)
$$

Each of the terms in Equation (1) is identified and interpreted individually as follows:

$$
\begin{gathered}
E_{\text {Nernst }}=E^{0}+\alpha_{1}\left(T-T_{0}\right)+\frac{R T}{2 F} \ln \left(P_{\mathrm{H}_{2}} \sqrt{P_{\mathrm{O}_{2}}}\right) \\
V_{\text {act }}=-\left[\zeta_{1}+\zeta_{2} T+\zeta_{3} T \ln \left(C_{\mathrm{O}_{2}}\right)+\zeta_{4} T \ln (I)\right] \\
C_{\mathrm{O}_{2}}=\frac{P_{O_{2}}}{5.08 \times 10^{6}} \exp \left(\frac{498}{T}\right)
\end{gathered}
$$

where, $E^{0}=1.229$ is the standard-state reversible fuel cell thermodynamic voltage are only useful under standard-state conditions (equal to $1.229 \mathrm{~V}$ at $298.15 \mathrm{~K}$ and $1 \mathrm{~atm}$ ). The coefficient $\alpha_{1}=\left(d E_{N e r s t} / d T\right)_{p}$ depends on the thermodynamic equilibrium potential, in the literature is determined from the entropy change of a given reaction which is approximately constant and can be set to the standard state value $-0.83 .10^{-3} \mathrm{~V} / \mathrm{K}, R$ is the gas constant, $8.3143 \mathrm{~J} / \mathrm{mol} .(\mathrm{K}), F$ is the Faraday's constant, equal to $96487 \mathrm{C} / \mathrm{mol}$, $P_{\mathrm{H}_{2}}$ is the hydrogen partial pressure at anode catalyst/gas interface (atm), $P_{O_{2}}$ the oxygen partial pressure at cathode catalyst/gas interface (atm), $T$ is the absolute cell temperature (Kelvin) and $T_{0}=298.15$ is the standard state temperature (Kelvin). The parametric coefficient $\zeta_{i}(i=1,2,3,4)$ represents the semi-empirical coefficients based on fluid mechanics, thermodynamics, and electrochemistry. The $C_{o_{2}}$ is the oxygen concentration at the catalytic interface of the cathode defined according to Henry's law $\left(\right.$ mol.cm $\left.^{-3}\right)$.

The ohmic loss in the FC can be mathematically interpreted as:

$$
V_{\text {ohmic }}=i\left(R_{m}+R_{c}\right)
$$

where $i$ is the cell operating current $(I), R_{m}$ denotes the membrane resistance $(\Omega)$ and $R_{c}$ denotes the equivalent resistance describing the concentration processes $\left(\Omega \mathrm{cm}^{-2}\right)$. The membrane resistance $R_{m}$ and $\rho_{m}$ denotes the specific resistance of the material of the membrane $(\Omega . \mathrm{cm})$, they can be evaluated as given in Equation (6).

$$
\left\{\begin{array}{c}
R_{m}=\rho_{m} \frac{l}{A} \\
\rho_{m}=\frac{181.6\left[1+0.03(i / A)+0.062(T / 303)^{2}(i / A)^{2.5}\right]}{\left[\lambda-0.634-3(i / A) \exp \left(4.18 \frac{T-303}{T}\right)\right]}
\end{array}\right.
$$

where, $\lambda$ is an adjustable empirical coefficient that influenced by the preparation steps of the solid membrane and $l$ is the membrane thickness $(\mu \mathrm{m})$.

The concentration voltage drop is given by:

$$
V_{\text {con }}=-\beta \ln \left(1-J / J_{\max }\right)
$$

where $\beta$ is a parametric coefficient $(V), J$ and $J_{\max }$ represent the actual and the maximum current of the cell $\left(\right.$ A.cm $\left.{ }^{-2}\right)$, respectively. 


\section{Bézier Curve Method}

The Bézier curve technique is defined as a parametric based in the spline or fitting curve, which forms the basis of the Bernstein function and control points. A Bézier curve $P(t)$ of degree $n$ in space $R^{m}$ with the $b_{i}$ as the control point is defined as follows:

$$
\begin{gathered}
p(t)=\sum_{i=0}^{n} b_{i} B_{i}^{n}(t) \\
\left\{\begin{array}{c}
b_{i}\left(x_{i, 1}, x_{i, 2} \cdots x_{i, m}\right) \in R^{m}, 0<i<n, t \in\left[\begin{array}{ll}
0 & 1
\end{array}\right] \\
B_{i}^{n}(t)=\frac{n !}{i !(n-i) !}(1-t)^{n-i} t^{i}
\end{array}\right.
\end{gathered}
$$

where $B_{i}{ }^{n}$ is the Bernstein basis functions and the coordination of the control points as $p_{i}\left(t_{i}, b_{i}\right)$.

The control points use the Greville abscissa $t_{i}=i / n$ to provide a kind of parametrization for various approximation polygons of the original Bézier curve using the subdivision process. Noting that the subdivision is an essential form in geometric modeling. In practice, the subdivision offers an attractive method for interpolation. Intersections of curves can also be determined by subdivision within any given tolerance $[1,54]$. Theoretical characteristics of the subdivision scheme also characterize specific geometric characteristics of the curve.

The subdivision of the curve using the Bézier curve method is obtained using the set of control points $b_{i}$ to find the new coordinate in the curve. The points are subdivided into two segments, and each segment possesses a Bézier polygon as follows:

$$
b_{0}, \frac{b_{0}+b_{1}}{2}, \frac{b_{1}+b_{2}}{2}, \ldots, \frac{b_{n-2}+b_{n-1}}{2}, \frac{b_{n-1}+b_{n}}{2}, b_{n}
$$

Figure 2 illustrates the degree elevation of a cubic Bézier piece with $b_{0}$ and $b_{4}$ are the content and ending points, respectively, and the points $c_{1}, \ldots, c_{5}$ are the connecting or midpoint points. The points from $b_{2}, \ldots, b_{2}$ are the control points of the curve. The curve constructed by the control points is called control polygon. The subdivision of the FC characteristic voltage-current curve using the Bézier curve method is illustrated in Figure 2.

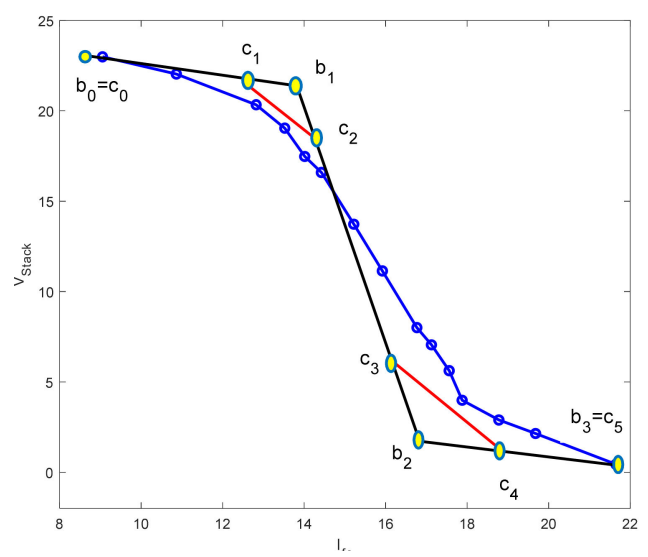

Figure 2. Degree elevation of Bézier curve applied to FC characteristic voltage-current curve.

The subdivision and evaluation can be obtained easily by using de Casteljau's algorithm applied to Equation (8). Let us define the new formulation based on the recurrence relation as follow:

$$
\left\{\begin{array}{cc}
b_{i}^{0}(t)=b_{i} & i=0, \cdots ; n \\
b_{i}^{r}(t)=(1-t) b_{i}^{r-1}(t)+t b_{i+1}^{r-1}(t) & r=1, \cdots, n ; i=0, \cdots ; n-r
\end{array}\right.
$$


The $p(t)=b_{0}^{n}(t)$ and let us consider any curve defined by:

$$
d(t)=\sum_{n=0}^{n} d_{n}(t) b_{n}
$$

Equation (12) belongs to the class of the curves that can be evaluated by the de Casteljau algorithm by changing the variable $t$ to a linear function nonconstant. The evaluation of the Bernstein polynomial begins with choosing a point $t_{0}$ to evaluate and subdivide the curve by using the diagonals of the triangle scheme to construct a division of the polynomial. The new evaluation can be formulated as follows:

$$
\left\{\begin{array}{cc}
b_{i}^{0}(t)=b_{i} & i=0, \cdots ; n \\
b_{i}^{r}(t)=\left(1-L_{i}^{r}(t)\right) b_{i}^{r-1}(t)+L_{i}^{r}(t) b_{i+1}^{r-1}(t) & r=1, \cdots, n ; i=0, \cdots ; n-r \\
L_{i}^{r}(t)=\frac{t-t_{0}}{1-t_{0}} & t_{0} \in[01]
\end{array}\right.
$$

The points $b_{0}^{n}(t)$ are obtained by the de Casteljau algorithm, which provides not only a procedural approach to the subdivision, but also an attractive graphical representation of the points $b_{0}^{n}(t)$. Figures 3 and 4 illustrate the diagram of the de Casteljau algorithm applied to the control points of the Bézier curve for $n=3$ and the relationship between $d(t)=b_{0}^{n}(t)$ and $L_{i}^{r}(t)$, respectively.

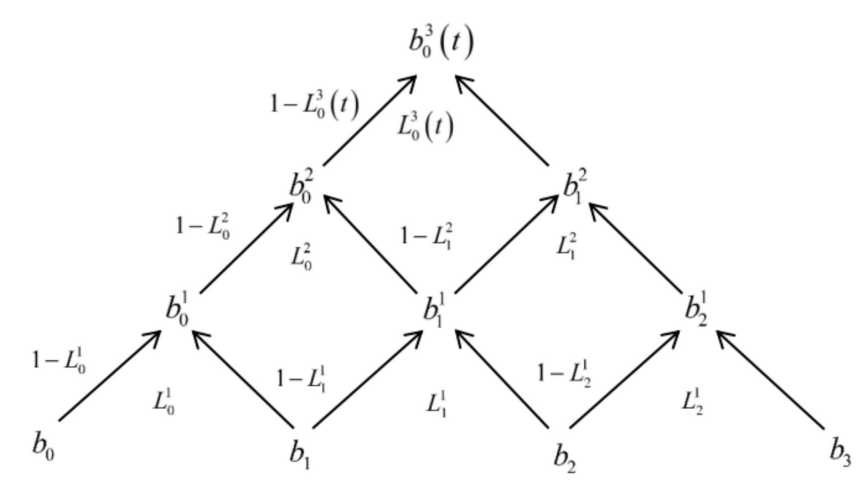

Figure 3. Diagram of the de Casteljau algorithm for $n=3$.

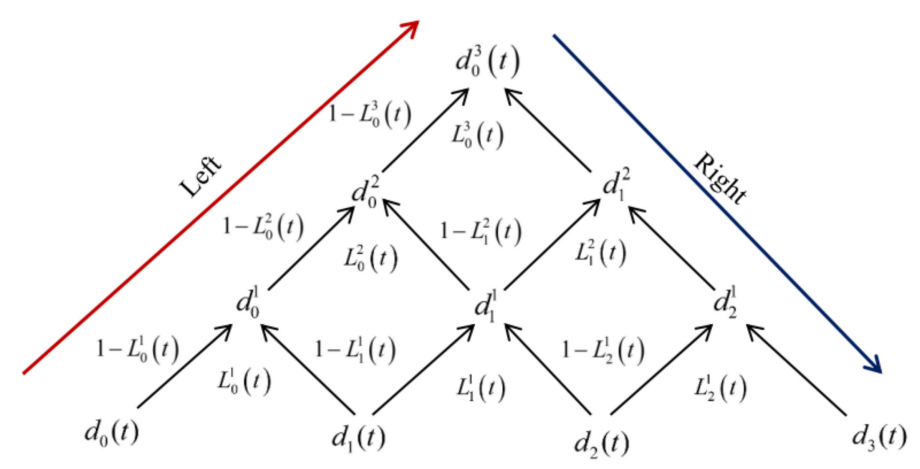

Figure 4. Relationship between $\mathrm{L}$ and $\mathrm{d}$ in the diagram of the de Casteljau algorithm for $n=3$.

Since the control points $b_{0}^{n}(t)$ are intermediate points in the de Casteljau evaluation algorithm, an optimization approach may be used to evaluate them adequately. This algorithm also provides the subdivision of the Bézier curve.

The subdivision step consists of dividing the curve described by $d(t)$ into two Bézier curves. In the fixed parameter $r \in[01]$, the first curve corresponds to the section range $[0 r]$, and the second 
parameter range $[r 1]$. Formally, the above curves are the Bezier curves related to $p_{\text {left }}(t)=(r t)$ and $p_{\text {righ }}(t)=p[r+t(1-r)]$ for $t \in[01]$. The new control points at left and right section at $t$ are given as:

$$
\left\{\begin{array}{cc}
p_{0}^{0}(t), p_{0}^{1}(t), p_{0}^{2}(t), \cdots, p_{0}^{n}(t) & \text { Left } \\
p_{0}^{n}(t), p_{1}^{n-1}(t), p_{1}^{n-2}(t), \cdots, p_{n}^{0}(t) & \text { Right }
\end{array}\right.
$$

The algebraic interpretation of the subdivision can also be written in terms of matrix multiplication as:

$$
\left\{\begin{array}{c}
D(t)=\left[d_{0}(t), d_{1}(t), \cdots, d_{n}(t)\right] \\
p=\left[p_{0}, p_{1}, \cdots, p_{n}\right] \\
p_{l}(t)=\left[p_{0}^{0}(t), p_{0}^{1}(t), p_{0}^{2}(t), \cdots, p_{0}^{n}(t)\right] \\
p_{r}(t)=\left[p_{0}^{n}(t), p_{1}^{n-1}(t), p_{1}^{n-2}(t), \cdots, p_{n}^{0}(t)\right]
\end{array}\right.
$$

From Figures 2 and 3 , the equations of the right and left section are given as follows:

$$
\left\{\begin{aligned}
S_{l}(t) & =\prod_{n=1}^{r} L^{n}{ }_{r-n}(t) \\
S_{r}(t) & =\prod_{n=1}^{n-r}\left[1-L^{n}{ }_{r}(t)\right]
\end{aligned}\right.
$$

The final equation of the experimental points is the sum of the right and left sections:

$$
S(t)=\prod_{n=1}^{r} L_{r-n}^{n}(t)+\prod_{n=1}^{n-r}\left[1-L_{r}^{n}(t)\right]
$$

\section{Proposed Method Evaluation Criteria}

Statistical criteria are widely used in numerous disciplines to evaluate the fitness of the theoretical or estimated model accurately. The assessment of the estimated models has been based on a comparison of the statistical criteria used to check the accuracy and efficiency of the simulations. To calculate the accuracy and performance of the Bézier curve method, the following statistical measures are used [55,56]:

Individual Absolute Error (IAE): it is the correlation between the observational current, voltage, or power points and the calculated current points using a methodology. It is defined as:

$$
I A E=\left|V_{m, i}-V_{c a l, i}\right|
$$

Relative Error (RE): It is used as a calculation of accuracy, and it is described as the ratio of the $I A E$ of the measurement to the calculations being recorded. $R E$ is expressed in terms and does not have any units, and it is expressed as:

$$
R E=\frac{\left|V_{m, i}-V_{c a l, i}\right|}{V_{m, i}}
$$

Root Mean Square Error (RMSE): it represents the probability distribution between the experimental and the presented curve data of the $m$ data point sample. This measure will be used to quantify unconsidered error that can be defined as follows:

$$
\text { RMSE }=\sqrt{\frac{1}{m} \sum_{i=1}^{m}\left(V_{m, i}-V_{c a l, i}\right)^{2}}
$$

Mean Bias Error (MBE): it represents the arithmetic mean of the error and provides information about the long-term performance; the small value is desired as a condition. It can signify whether 
the model overestimates or underestimates. $M B E$ quantifies the systematic error, and it is described as follows:

$$
M B E=\frac{1}{m} \sum_{i=1}^{m}\left(V_{m, i}-V_{c a l, i}\right)
$$

Autocorrelation Function (ACF): it defines how the correlation between any two values of the signal changes as their separation changes. It is a time-domain measure of the stochastic process memory, and it does not reveal any information about the frequency content of the process. For error signal $e_{t}$, the $A C F$ can be formulated as:

$$
A C F=\frac{\operatorname{Conv}\left(e_{t}, e_{t+k}\right)}{\sqrt{\operatorname{Var}\left(e_{t}\right) \operatorname{Var}\left(e_{t+k}\right)}}
$$

\section{Results, Discussions, and Comparisons}

In this section, the performance and validity of the proposed method are investigated for characteristic curves approximation of four well-known commercial PEMFC by M/S Ballard Systems, Horizon H-12 W stack, NedStackPS6 PEMFC stack, and 250 W PEMFC stack. The datasheet specifications of these four commercial PEMFCs stacks are concluded from [14,25,49,50], and represented in Table 1, respectively. The measured experimental data characteristic curves of these four FCs are accessible online and reproducible in the literature in terms of parameter and curves estimation by several researchers $[14,19,38,46]$.

Table 1. Datasheet specifications of different stacks.

\begin{tabular}{cccccccc}
\hline Fuel Cell & $\boldsymbol{n}_{\text {cell }}$ & $\boldsymbol{A ( \mathbf { c m } ^ { 2 } )}$ & $\boldsymbol{l}(\boldsymbol{\mu m})$ & $\boldsymbol{P}_{\boldsymbol{H} 2}$ (bar) & $\boldsymbol{P}_{\boldsymbol{o} \mathbf{2}}$ (bar) & $\boldsymbol{T} \mathbf{( K )}$ & $\boldsymbol{R H}_{\boldsymbol{a}}, \boldsymbol{R H}_{\boldsymbol{c}}$ \\
\hline M/S Ballard [50] & 35 & 50.6 & 178 & 1 & 1 & 343 & 1 \\
Horizon H-12 [14,57] & 13 & 8.1 & 25 & 0.4935 & 1 & 302.15 & 1 \\
NedStack PS6 [25] & 65 & 240 & 178 & $0.5-5$ & $0.5-5$ & 343 & 1 \\
250 W [49] & 24 & 27 & 178 & 1 & 0.2075 & $343.15-353.15$ & 1 \\
\hline
\end{tabular}

The efficiency of the proposed effective computer graphic technique used to approximate the FC characteristics curve is compared with various algorithms to validate the performance of each algorithm. Further, statistical metrics are calculated and evaluated using the most used statistical criteria and error analysis in the research literature. The important is to identify the performance method in others by comparing each V-I and P-I curves.

\subsection{Case Study 1: Single Cell-Based PEMFC by M/S Ballard Systems}

The proposed computer graphic technique is applied first to approximate the voltage-current and P-I curves of the M/S Ballard Systems rated power fuel cell system. This stack has 35 cells connected in a series with $70 \mathrm{~A}$ maximum thermal current. The main information and the characteristics of this FC are reported in Table 1. The pair measured experimental data are collected from [19]. The experimental data of M/S Ballard Systems have been widely used to extract and estimate the unknown parameters and then approximate their characteristic curves. Table 2 reports the approximated current and voltage using the Bézier curve method compared with GRG-1 [22], GRG-2 [22], GGHS [50], IHS [50], and PSO-w [50]. Further, the IAE of the approximated characteristics are evaluated and compared. 
Table 2. Comparison results of the approximated voltage, current, and IAE of M/S Ballard Systems.

\begin{tabular}{|c|c|c|c|c|c|c|c|c|c|}
\hline \multicolumn{2}{|c|}{ Experimental } & \multicolumn{2}{|c|}{ Bézier Curve } & \multicolumn{6}{|c|}{$I A E$} \\
\hline$I_{e x}$ & $V_{e x}$ & $V_{b}$ & $I_{b}$ & Bézier Curve & GRG-1 [22] & GRG-2 [22] & GGHS [50] & IHS [50] & PSO-w [50] \\
\hline 5.4 & 0.92 & 5.423 & 0.9185 & $1.50 \times 10^{-3}$ & $2.9 \times 10^{-3}$ & $1.52 \times 10^{-2}$ & $3.2 \times 10^{-3}$ & $1.41 \times 10^{-2}$ & $2.07 \times 10^{-2}$ \\
\hline 10.8 & 0.88 & 10.8105 & 0.8803 & $3.00 \times 10^{-4}$ & $2.1 \times 10^{-3}$ & $2 \times 10^{-3}$ & $1.7 \times 10^{-3}$ & $2.4 \times 10^{-3}$ & $1.36 \times 10^{-2}$ \\
\hline 16.2 & 0.85 & 16.1271 & 0.8495 & $5.00 \times 10^{-4}$ & $1.6 \times 10^{-3}$ & $5.8 \times 10^{-3}$ & $3.5 \times 10^{-3}$ & $2.9 \times 10^{-3}$ & $1.04 \times 10^{-2}$ \\
\hline 21.6 & 0.82 & 21.5855 & 0.8202 & $2.00 \times 10^{-4}$ & $3 \times 10^{-3}$ & $7.5 \times 10^{-3}$ & $1 \times 10^{-4}$ & $1.6 \times 10-$ & $1.28 \times 10^{-2}$ \\
\hline 27.0 & 0.79 & 27.044 & 0.7894 & $6.00 \times 10^{-4}$ & $5.1 \times 10^{-3}$ & $5.8 \times 10^{-3}$ & $6.5 \times 10^{-3}$ & $3.2 \times 10^{-3}$ & $1.81 \times 10^{-2}$ \\
\hline 32.4 & 0.77 & 32.4315 & 0.7689 & $1.10 \times 10^{-3}$ & $2.3 \times 10^{-3}$ & $1.23 \times 10^{-2}$ & $4.4 \times 10^{-3}$ & $1 \times 10^{-4}$ & $1.51 \times 10^{-2}$ \\
\hline 37.8 & 0.74 & 37.7481 & 0.7381 & $1.90 \times 10^{-3}$ & $5 \times 10^{-4}$ & $7.5 \times 10^{-3}$ & $1.34 \times 10^{-2}$ & $8.2 \times 10^{-3}$ & $2.31 \times 10^{-2}$ \\
\hline 43.2 & 0.72 & 43.1356 & 0.719 & $1.00 \times 10^{-3}$ & $6.9 \times 10^{-3}$ & $1.21 \times 10^{-2}$ & $1.29 \times 10^{-2}$ & $7.1 \times 10^{-3}$ & $2.16 \times 10^{-2}$ \\
\hline 48.6 & 0.69 & 48.5232 & 0.6882 & $1.80 \times 10^{-3}$ & $4.6 \times 10^{-3}$ & $6.4 \times 10^{-3}$ & $2.25 \times 10^{-2}$ & $1.62 \times 10^{-2}$ & $3 \times 10^{-2}$ \\
\hline 54.0 & 0.66 & 53.9107 & 0.6589 & $1.10 \times 10^{-3}$ & $3 \times 10^{-3}$ & $9 \times 10^{-4}$ & $3.18 \times 10^{-2}$ & $2.5 \times 10^{-2}$ & $3.78 \times 10^{-2}$ \\
\hline 59.4 & 0.62 & 59.3691 & 0.6178 & $2.20 \times 10^{-3}$ & $7.3 \times 10^{-3}$ & $1.37 \times 10^{-2}$ & $5.02 \times 10^{-2}$ & $4.27 \times 10^{-2}$ & $5.35 \times 10^{-2}$ \\
\hline 64.8 & 0.60 & 64.8275 & 0.5987 & $1.30 \times 10^{-3}$ & $5 \times 10^{-3}$ & $6 \times 10^{-3}$ & $4.62 \times 10^{-2}$ & $3.78 \times 10^{-2}$ & $4.2 \times 10^{-2}$ \\
\hline 70.2 & 0.55 & 70.1441 & 0.5489 & $1.10 \times 10^{-3}$ & $5.4 \times 10^{-3}$ & $2.13 \times 10^{-2}$ & $6.52 \times 10^{-2}$ & $5.43 \times 10^{-2}$ & $6.31 \times 10^{-2}$ \\
\hline
\end{tabular}

To present more validity and accuracy of the proposed method, the reconstructions of the V-I and P-I are presented in Figure 5a,b. The reconstructed approximated characteristics curves are compared with the experimental data point and GRG-1, GRG-2, GGHS, IHS, and PSO-w. The results of validation and approximation curves denote an excellent match compared with empirical data and other algorithms. From Figure 5, it is shown that the two algorithms GRG-1 and GRG-2 are close to experimental data in low voltage while in high voltage, they are far. The other algorithm approximated the two curves by high errors in high and low voltages.

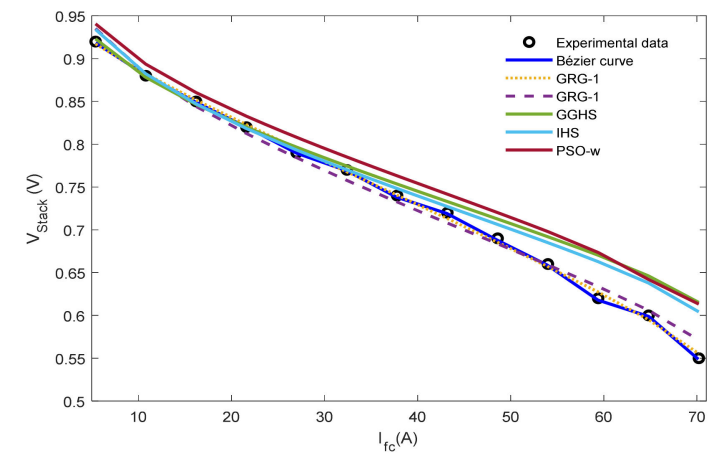

(a)

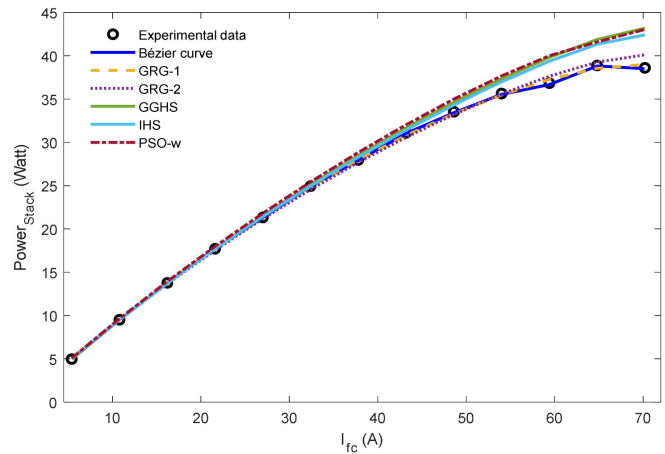

(b)

Figure 5. (a) V-I and (b) P-I compared experimental data and model calculated results of M/S Ballard systems.

Figure 6 illustrates the comparison of the approximated voltage of M/S Ballard system with the experimental and the values obtained by the algorithms GRG-1, GRG-2, GGHS, IHS and PSO-w. The comparison illustrates and demonstrates that the Bézier curve method shows an excellent correlation between the approximated voltages and the experimental voltage. 


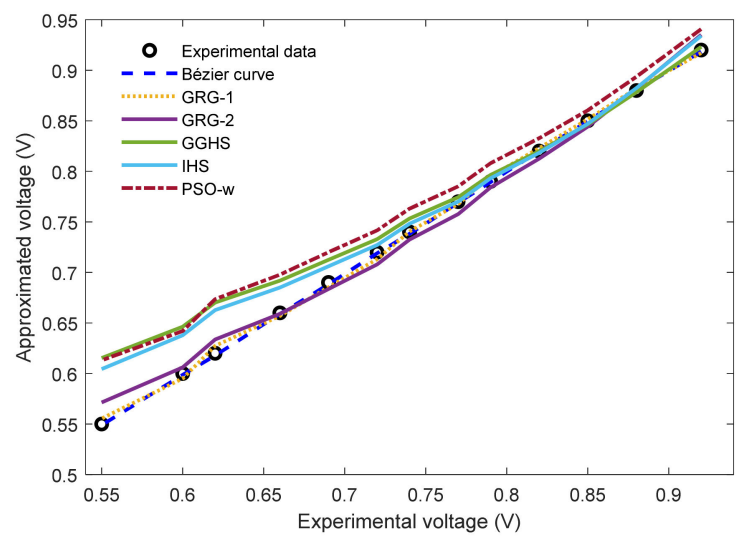

Figure 6. Compared calculated voltage with experimental of M/S Ballard Systems.

To confirm the performance of the proposed method and present more accuracy of each technique, the IAE and $R E$ are presented and compared in Figure 7a,b, respectively. From Figure 7a,b, the lowest values of the $I A E$ and $R E$, which indicate the advantages of the Bézier curve method, are demonstrated. Further, the obtained lower values using the Bézier curve method present the performance of the proposed method concerning GRG-1, GRG-2, GGHS, IHS, and PSO-w.

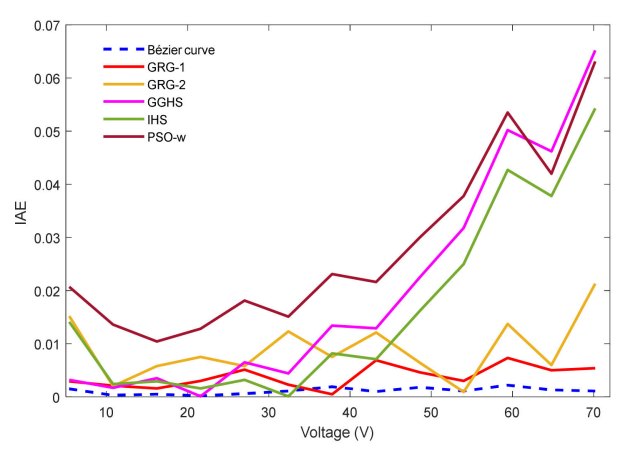

(a)

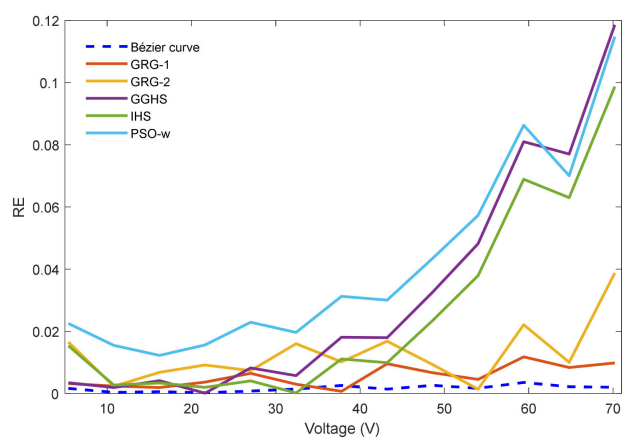

(b)

Figure 7. (a) $I A E$ and (b) RE of M/S Ballard Systems.

Moreover, the $A C F$ is evaluated as shown in Figure 8. The presented qualified test of the M/S Ballard Systems is in the range of -1 and +1 .

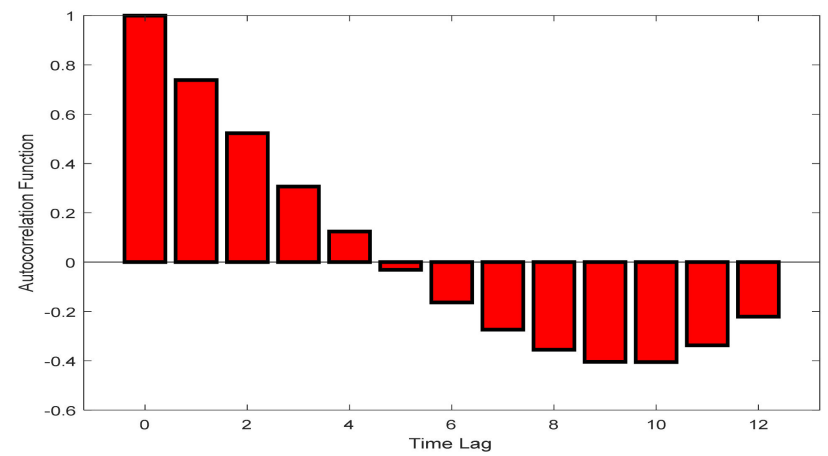

Figure 8. $A C F$ of M/S Ballard Systems. 


\subsection{Case Study 2: Horizon H-12 W Stack}

The second case study is about the approximation of the characteristic curves of Horizon H-12 $12 \mathrm{~W}$. The primary information and characteristics datasheet of this fuel cell are reported in Table 2. The primary objective of this test case study was to validate the implementation of Bézier curve method compared to WOA [14], GA [38], and MRFO [38] for the effective determination of voltage, current and power of Horizon H-12 PEMFC stack. The measured pairs current and experimental voltage data of PEMFC stack are collected from $[14,38]$, in which the fuel cell is operated at a normal atmospheric pressure of 0.5 bar and the ambient temperature of $29^{\circ} \mathrm{C}$. The main configuration for this fuel cell illustrated in Table 2. A 19 experimental pair measurements of current-voltage characteristics are used under the cited steady-state conditions illustrated in Table 3.

Table 3. Comparison of the approximated values and IAE of Horizon H-12 W stack.

\begin{tabular}{|c|c|c|c|c|c|c|c|}
\hline \multicolumn{2}{|c|}{ Experimental } & \multicolumn{2}{|c|}{ Bézier Curve } & \multicolumn{4}{|c|}{$I A E$} \\
\hline$I_{e x}$ & $V_{e x}$ & $I_{b}$ & $V_{b}$ & Bézier Curve & WOA [14] & GA [38] & MRFO [38] \\
\hline 0.104 & 9.58 & 0.1032 & 9.5732 & $8.00 \times 10^{-4}$ & $1.51 \times 10^{-1}$ & $1.69 \times 10^{-1}$ & $1.64 \times 10^{-1}$ \\
\hline 0.2 & 9.42 & 0.2010 & 9.4153 & $1.00 \times 10^{-3}$ & $3.00 \times 10^{-2}$ & $4.70 \times 10^{-2}$ & $4.10 \times 10^{-2}$ \\
\hline 0.309 & 9.25 & 0.3097 & 9.2510 & $7.00 \times 10^{-4}$ & $4.00 \times 10^{-3}$ & $1.20 \times 10^{-2}$ & $5.00 \times 10^{-3}$ \\
\hline 0.403 & 9.2 & 0.4032 & 9.1984 & $2.00 \times 10^{-4}$ & $9.00 \times 10^{-2}$ & $7.40 \times 10^{-2}$ & $8.20 \times 10^{-2}$ \\
\hline 0.51 & 9.09 & 0.5097 & 9.0866 & $3.00 \times 10^{-4}$ & $1.09 \times 10^{-1}$ & $9.40 \times 10^{-2}$ & $1.04 \times 10^{-1}$ \\
\hline 0.614 & 8.95 & 0.6141 & 8.9485 & $1.00 \times 10^{-4}$ & $8.00 \times 10^{-2}$ & $6.60 \times 10^{-2}$ & $7.70 \times 10^{-2}$ \\
\hline 0.703 & 8.85 & 0.7032 & 8.8564 & $2.00 \times 10^{-4}$ & $6.60 \times 10^{-2}$ & $5.20 \times 10^{-2}$ & $6.50 \times 10^{-2}$ \\
\hline 0.806 & 8.74 & 0.8076 & 8.7447 & $1.60 \times 10^{-3}$ & $4.90 \times 10^{-2}$ & $3.60 \times 10^{-2}$ & $5.00 \times 10^{-2}$ \\
\hline 0.908 & 8.65 & 0.9076 & 8.6526 & $4.00 \times 10^{-4}$ & $4.50 \times 10^{-2}$ & $3.30 \times 10^{-2}$ & $4.90 \times 10^{-2}$ \\
\hline 1.076 & 8.45 & 1.075 & 8.4488 & $1.00 \times 10^{-3}$ & $2.10 \times 10^{-2}$ & $3.10 \times 10^{-2}$ & $1.30 \times 10^{-2}$ \\
\hline 1.127 & 8.41 & 1.1271 & 8.4093 & $1.00 \times 10^{-4}$ & $2.20 \times 10^{-2}$ & $3.20 \times 10^{-2}$ & $1.30 \times 10^{-2}$ \\
\hline 1.288 & 8.2 & 1.2902 & 8.1989 & $2.20 \times 10^{-3}$ & $1.13 \times 10^{-1}$ & $1.21 \times 10^{-1}$ & $9.90 \times 10^{-2}$ \\
\hline 1.39 & 8.12 & 1.3902 & 8.1200 & $2.00 \times 10^{-4}$ & $1.19 \times 10^{-1}$ & $1.26 \times 10^{-1}$ & $1.03 \times 10^{-1}$ \\
\hline 1.45 & 8.11 & 1.4510 & 8.1068 & $1.00 \times 10^{-3}$ & $8.60 \times 10^{-2}$ & $9.30 \times 10^{-2}$ & $6.90 \times 10^{-2}$ \\
\hline 1.578 & 8.05 & 1.5793 & 8.0477 & $1.30 \times 10^{-3}$ & $5.70 \times 10^{-2}$ & $6.20 \times 10^{-2}$ & $3.60 \times 10^{-2}$ \\
\hline 1.707 & 7.99 & 1.7076 & 7.9951 & $6.00 \times 10^{-4}$ & $2.80 \times 10^{-2}$ & $3.20 \times 10^{-2}$ & $3.00 \times 10^{-3}$ \\
\hline 1.815 & 7.95 & 1.8163 & 7.9490 & $1.30 \times 10^{-3}$ & $6.00 \times 10^{-3}$ & $3.00 \times 10^{-3}$ & $3.50 \times 10^{-2}$ \\
\hline 1.9 & 7.94 & 1.9010 & 7.9359 & $1.00 \times 10^{-3}$ & $5.40 \times 10^{-2}$ & $5.20 \times 10^{-2}$ & $8.50 \times 10^{-2}$ \\
\hline 2.06 & 7.9 & 2.0597 & 7.8964 & $3.00 \times 10^{-4}$ & $1.23 \times 10^{-1}$ & $1.23 \times 10^{-1}$ & $1.00 \times 10^{-1}$ \\
\hline
\end{tabular}

Table 3 depicts the approximated voltage and current by Bézier curve method compared with the measured experimental data. Moreover, Table 3 illustrates the comparison of the IAE of Bézier curve method with WOA, GA, and MRFO.

The reproduced V-I and P-I curves using the approximated Bézier curve method compared with the experimental data are presented in Figure 9a,b. Moreover, the quality and efficiency of the approximated values are reconstructed and compared with WOA, GA, and MRFO. It is clear that the reconstructed curves using the Bézier curve method are close to the experimental data. 


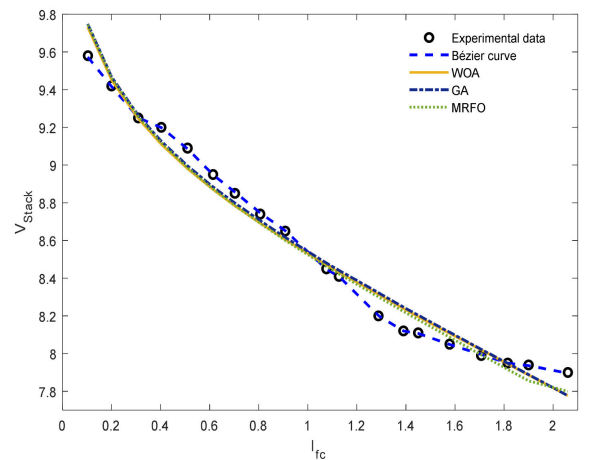

(a)

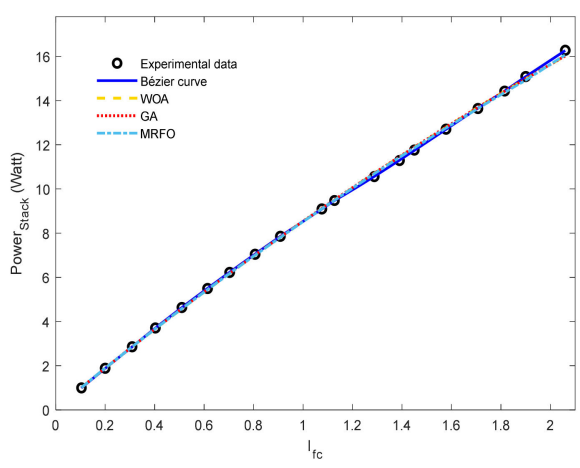

(b)

Figure 9. Comparison of (a) I-V and (b) P-V with experimental data and model calculated results by WOA, GA, and MRFO of Horizon H-12 W Stack.

The accuracy of the Bézier curve method in the voltage approximation is illustrated in Figure 10. The approximated voltage is close to the experimental values, while the values obtained by WOA, GA, and MRFO are far. This shows that the proposed method outperforms the WOA, GA, and MRFO algorithms.

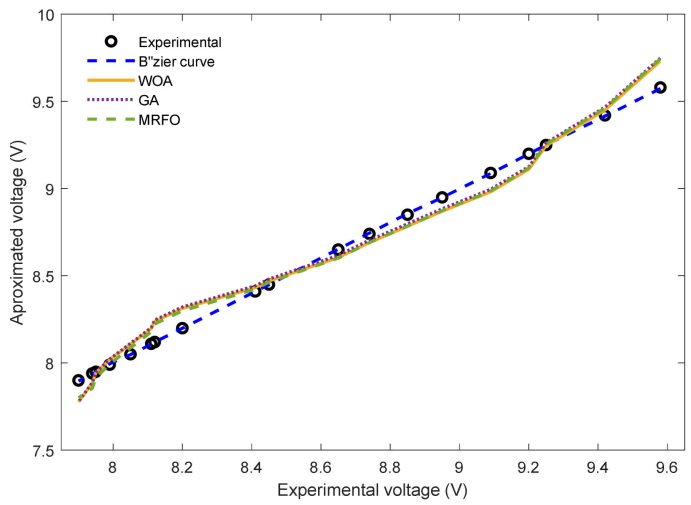

Figure 10. Compared calculated voltage with experimental for FC Horizon H-12 W Stack.

For more validity and accuracy, the statistical metrics in terms of $I A E$ and $R E$ are illustrated in Figure $11 \mathrm{a}, \mathrm{b}$. It is observed that the Bézier curve method provides the lowest value of $I A E$ and $R E$ compared to the algorithms WOA, GA, and MRFO.

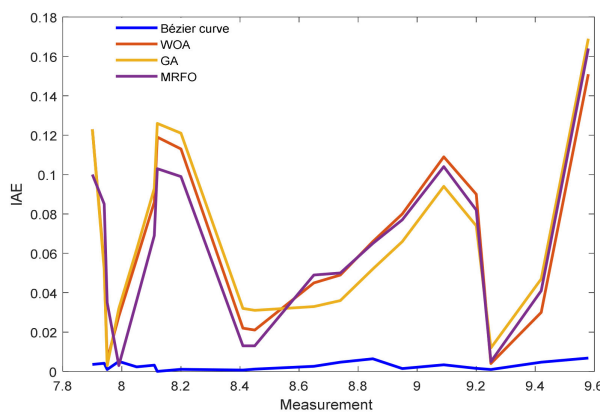

(a)

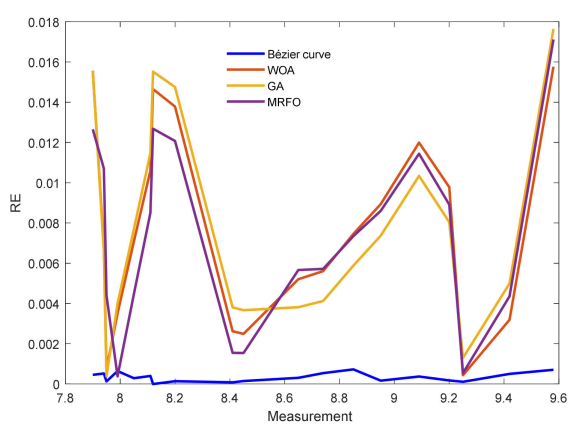

(b)

Figure 11. Comparison of (a) $I A E$ and (b) RE of FC Horizon H-12 W stack. 
Figure 12 presents the $A C F$ of the fuel cell Horizon $\mathrm{H}-1212 \mathrm{~W}$. The given qualified test is in the range of -1 and +1 .

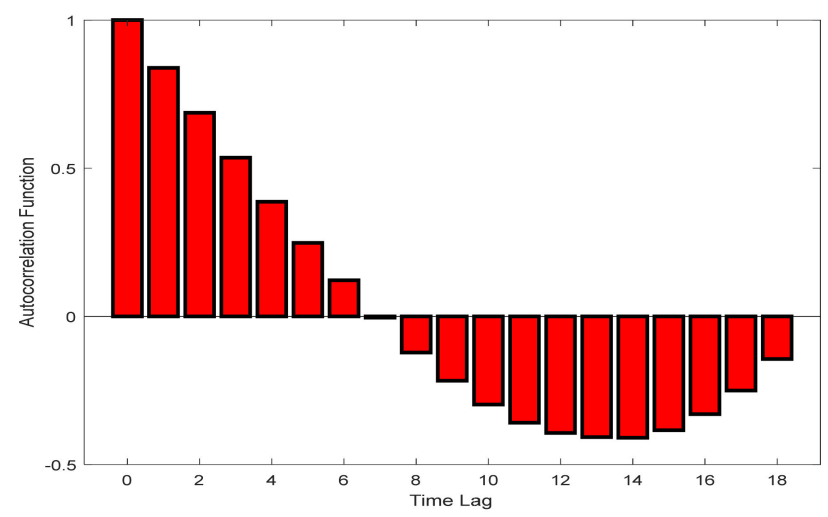

Figure 12. $A C F$ of the FC Horizon H-12 W Stack.

\subsection{Case Study 3: NedStackPS6 PEMFC Stack}

In this case study, a NedSstackPS6 PEMFC stack rated power fuel cell system has been analyzed for performance analysis of the Bézier curve method. The datasheet of the product is accumulated from [25] and reported in Table 2. The fuel cell is with 225 A maximum cell current, and operating partial pressures lie between 1 and 5 bar.

Table 4 present the approximated values obtained by Bézier curve method compared with the algorithms MRFO [38], FOA [25], ICA [25], SFLA [25], SMSA [26] and SSO [32].

Table 4. Comparison of the approximated values and IAE of NedStackPS6 PEMFC stack.

\begin{tabular}{|c|c|c|c|c|c|c|c|c|c|}
\hline \multicolumn{2}{|c|}{ Experimental } & \multicolumn{2}{|c|}{ Bézier Curve } & \multicolumn{6}{|c|}{$I A E$} \\
\hline$I_{e x}$ & $V_{e x}$ & $I_{b}$ & $V_{b}$ & Bézier Curve & MRFO [38] & FOA [25] & ICA & SMSA [26] & $\mathrm{SSO}[32]$ \\
\hline 2.25 & 61.64 & 2.2448 & 61.6528 & $1.28 \times 10^{-2}$ & 1.889 & 0.6265 & 0.6347 & 0.7158 & 0.7381 \\
\hline 6.75 & 59.57 & 6.4981 & 59.5867 & $1.67 \times 10^{-2}$ & 0.546 & 0.1246 & 0.1328 & 0.2118 & 0.2305 \\
\hline 9 & 58.94 & 9.0974 & 58.9256 & $1.44 \times 10^{-2}$ & 1.458 & 0.0244 & 0.0326 & 0.1104 & 0.1276 \\
\hline 15.75 & 57.54 & 15.714 & 57.5206 & $1.94 \times 10^{-2}$ & 0.832 & 0.1239 & 0.1155 & 0.0418 & 0.0286 \\
\hline 20.25 & 56.8 & 20.203 & 56.7768 & $2.32 \times 10^{-2}$ & 0.762 & 0.1595 & 0.1511 & 0.0805 & 0.0698 \\
\hline 24.75 & 56.13 & 24.693 & 56.1157 & $1.43 \times 10^{-2}$ & 0.976 & 0.1595 & 0.1511 & 0.0838 & 0.0755 \\
\hline 31.5 & 55.23 & 31.545 & 55.2066 & $2.34 \times 10^{-2}$ & 0.611 & 0.1412 & 0.1328 & 0.0711 & 0.066 \\
\hline 36 & 54.66 & 36.035 & 54.6280 & $3.20 \times 10^{-2}$ & 1.027 & 0.1038 & 0.0954 & 0.0378 & 0.0346 \\
\hline 45 & 53.61 & 45.014 & 53.6363 & $2.63 \times 10^{-2}$ & 0.665 & 0.0325 & 0.0242 & 0.0245 & 0.0241 \\
\hline 51.75 & 52.86 & 51.867 & 52.8925 & $3.25 \times 10^{-2}$ & 1.418 & 0.0359 & 0.0441 & 0.0853 & 0.0826 \\
\hline 67.5 & 51.91 & 67.462 & 51.9008 & $9.20 \times 10^{-3}$ & 0.88 & 0.4989 & 0.4911 & 0.4697 & 0.4763 \\
\hline 72 & 51.22 & 71.952 & 51.1570 & $6.30 \times 10^{-2}$ & 1.797 & 0.2152 & 0.2076 & 0.1923 & 0.1997 \\
\hline 90 & 49.66 & 89.910 & 49.5867 & $7.33 \times 10^{-2}$ & 1.027 & 0.2369 & 0.2301 & 0.2416 & 0.2502 \\
\hline 99 & 49 & 98.889 & 49.0082 & $8.20 \times 10^{-3}$ & 0.962 & 0.3535 & 0.3472 & 0.373 & 0.381 \\
\hline 105.8 & 48.15 & 105.74 & 48.1818 & $3.18 \times 10^{-2}$ & 0.506 & 0.0882 & 0.0824 & 0.1192 & 0.1261 \\
\hline 110.3 & 47.52 & 110.23 & 47.5206 & $6.00 \times 10^{-4}$ & 0.463 & 0.1547 & 0.1602 & 0.1161 & 0.1102 \\
\hline 117 & 47.1 & 117.08 & 47.1074 & $7.40 \times 10^{-3}$ & 0.836 & 0.0029 & 0.002 & 0.0527 & 0.0567 \\
\hline 126 & 46.48 & 126.06 & 46.3636 & $1.164 \times 10^{-1}$ & 1.016 & 0.1638 & 0.1598 & 0.2279 & 0.2285 \\
\hline 135 & 45.66 & 135.04 & 45.6198 & $4.02 \times 10^{-2}$ & 0.806 & 0.1337 & 0.1306 & 0.2106 & 0.2067 \\
\hline 141.8 & 44.85 & 141.9 & 44.7933 & $5.67 \times 10^{-2}$ & 0.814 & 0.0712 & 0.0736 & 0.0136 & 0.0056 \\
\hline 150.8 & 44.24 & 150.87 & 44.1322 & $1.078 \times 10^{-1}$ & 1.24 & 0.1336 & 0.1324 & 0.2254 & 0.2108 \\
\hline 162 & 42.45 & 161.98 & 42.4793 & $2.93 \times 10^{-2}$ & 0.3 & 0.6136 & 0.6131 & 0.5221 & 0.5467 \\
\hline 171 & 41.66 & 170.96 & 41.5702 & $8.98 \times 10^{-2}$ & 0.603 & 0.5354 & 0.5334 & 0.4557 & 0.4901 \\
\hline 182.3 & 40.68 & 182.3 & 40.6611 & $1.89 \times 10^{-2}$ & 0.286 & 0.3733 & 0.3693 & 0.3337 & 0.3824 \\
\hline 189 & 40.09 & 188.92 & 40.0826 & $7.40 \times 10^{-3}$ & 0.38 & 0.2491 & 0.2437 & 0.2546 & 0.3131 \\
\hline 195.8 & 39.51 & 195.77 & 39.5041 & $5.90 \times 10^{-3}$ & 0.727 & 0.0644 & 0.0575 & 0.1426 & 0.212 \\
\hline 204.8 & 38.73 & 204.75 & 38.7603 & $3.030 \times 10^{-2}$ & 0.654 & 0.2618 & 0.2707 & 0.0151 & 0.0705 \\
\hline 211.5 & 38.15 & 211.6 & 38.0991 & $5.09 \times 10^{-2}$ & 1.046 & 0.6296 & 0.6403 & 0.1504 & 0.0514 \\
\hline 220.5 & 37.38 & 220.58 & 37.37 & $1.00 \times 10^{-2}$ & 0.773 & 1.2377 & 1.654 & 0.3661 & 0.2472 \\
\hline
\end{tabular}

Figure 13a,b show the reconstructed V-I and P-I curves of NedStackPS6 PEMFC stack using the approximated value using Bézier curve method compared to experimental data and MRFO and FOA 
algorithms. The comparisons show that the reconstructed value using Bézier curve method is in good agreement with experimental data.

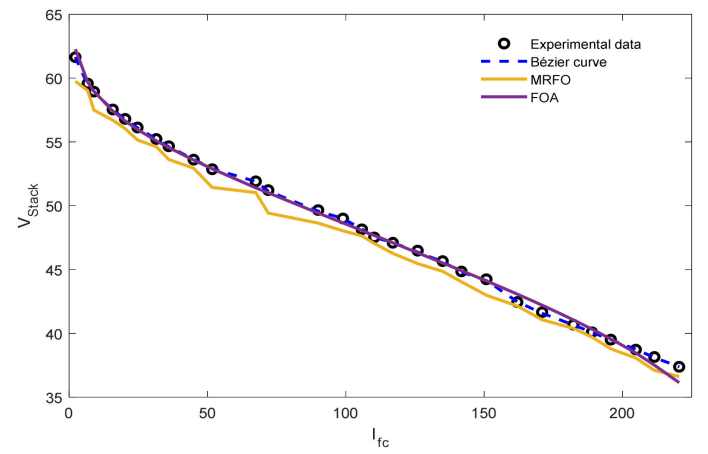

(a)

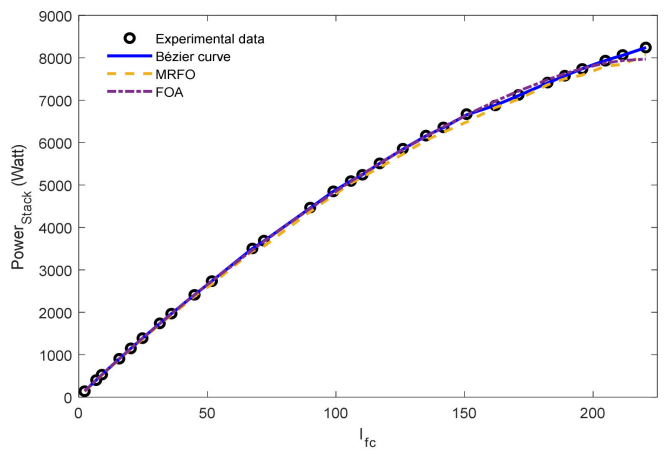

(b)

Figure 13. Comparison of (a) V-I and (b) P-I with experimental data and model calculated results by MRFO and FOA of NedStackPS6 PEMFC stack.

Figure 14 presents the comparison of the approximated voltage values with experimental and the value obtained by MRFO and DOA algorithms. The voltage value approximated by Bézier curve method is close to the experimental data better than the values obtained by MRFO and DOA algorithms.

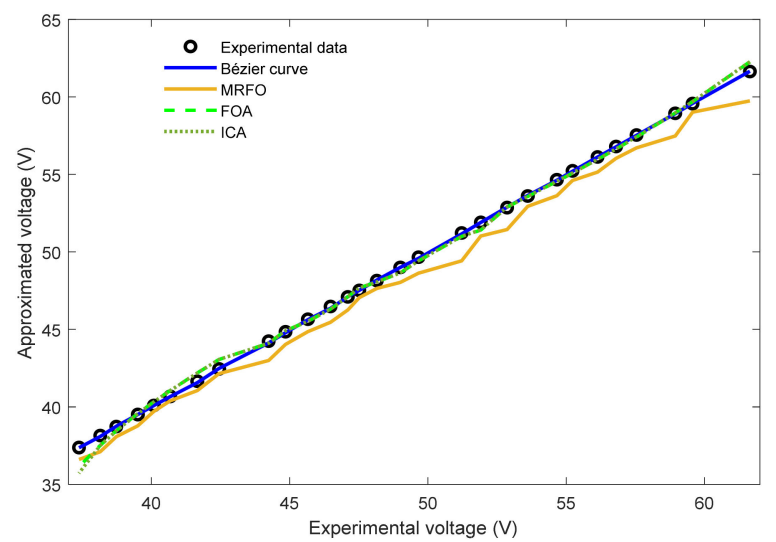

Figure 14. Compared calculated voltage with experimental of NedStack PS6 PEMFC stack.

The performance of the Bézier curve method provides the lowest values for the statistical criteria, $I A E$ and $M A E$, when compared to the other algorithms. Therefore, the Bézier curve method is ranked first in achieving the lowest of IAE and RE, while the ICA and FOA are ranked second and third, respectively. Therefore, the approximated values of the characteristic's curves identified by the proposed Bézier curve method are very accurate because they are close to the experimental data of the fuel cell. The $I A E$ and the RE for each measurement using optimal values founded by the Bézier curve method are depicted in Figure 15a,b. It observed that the Bézier curve method performs better than the reported algorithms. 


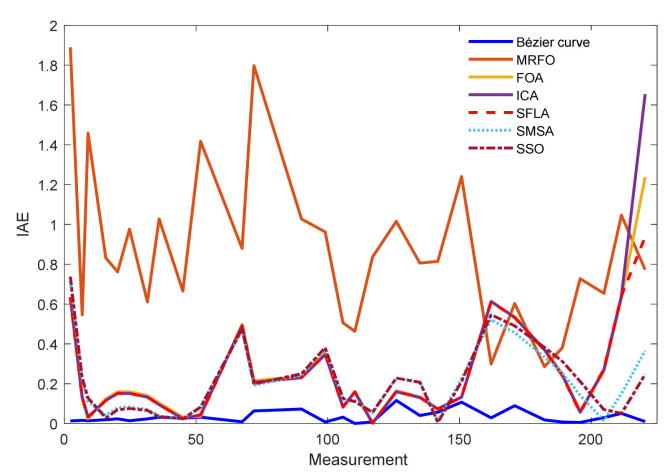

(a)

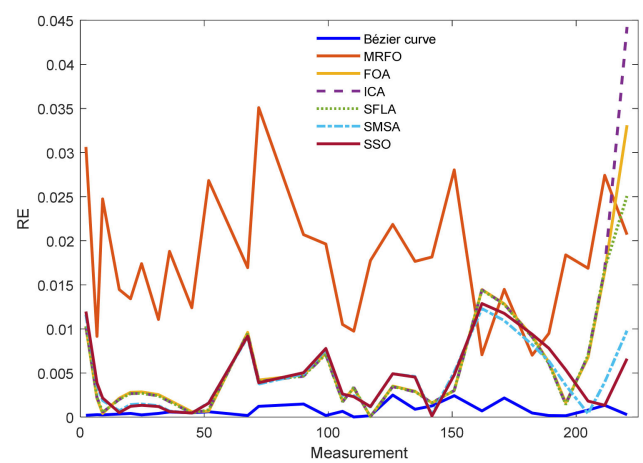

(b)

Figure 15. Compared (a) IAE and (b) RE of NedStack PS6 PEMFC stack.

Figure 16 illustrated the calculated ACF of the FC NedStackPS6 PEMFC stack. The presented values of the qualified test are in the range of -1 and +1 .

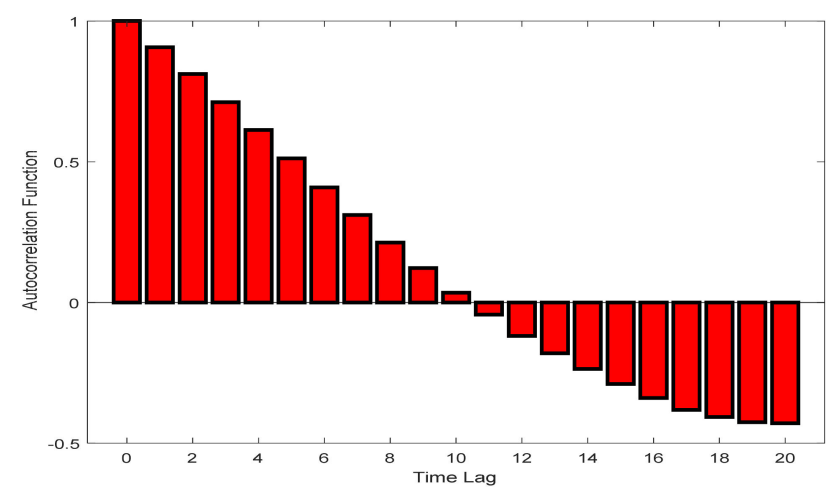

Figure 16. $A C F$ of the NedStack PS6 PEMFC stack.

\subsection{Case Study 4: 250 W PEMFC Stack}

The last case study deals with the approximation of the characteristics curve of the $250 \mathrm{~W}$ fuel cell stack. The measured end experimental current and voltage data are collected from [46]. This data is widely used in the parameters extraction and estimation to estimate the characteristic curve of the $250 \mathrm{~W}$ fuel cell stack. Moreover, the datasheets constant data of the product are reported in Table 2.

Table 4 presents the approximated value of current and voltage using the Bézier curve method compared with experimental data. The calculated IAE of the Bézier curve, CHHO [49], and MAEO [51] are compared and reported in Table 5. The purpose of the comparison is to validate the accuracy of the proposed technique in the characteristic curves process with other algorithms. 
Table 5. Comparison of the approximated value of $250 \mathrm{~W}$ PEMFC stack.

\begin{tabular}{ccccccc}
\hline \multicolumn{6}{c}{ Experimental } & \multicolumn{3}{c}{ Bézier Curve } & IAE & \\
\hline$I_{e x}$ & $V_{e x}$ & $I_{b}$ & $V_{b}$ & Bézier Curve & MAEO [49] & CHHO [51] \\
0.4717 & 21.63 & 0.44278 & 21.649 & $1.90 \times 10^{-2}$ & $1.20 \times 10^{-1}$ & 0.1741 \\
2.149 & 19.68 & 2.1458 & 19.678 & $2.00 \times 10^{-3}$ & $3.18 \times 10^{-1}$ & 0.333 \\
2.83 & 18.78 & 2.8951 & 18.778 & $2.00 \times 10^{-3}$ & $1.45 \times 10^{-1}$ & 0.1352 \\
3.983 & 17.88 & 3.985 & 17.878 & $2.00 \times 10^{-3}$ & $4.59 \times 10^{-1}$ & 0.4558 \\
5.713 & 17.58 & 5.6199 & 17.56 & $2.00 \times 10^{-2}$ & $6.45 \times 10^{-2}$ & 0.0662 \\
7.075 & 17.12 & 7.0504 & 17.124 & $4.00 \times 10^{-3}$ & $5.71 \times 10^{-2}$ & 0.0606 \\
8.019 & 16.77 & 8.0041 & 16.767 & $3.00 \times 10^{-3}$ & $1.06 \times 10^{-1}$ & 0.1103 \\
11.16 & 15.92 & 11.138 & 15.92 & $2.20 \times 10^{-2}$ & $1.85 \times 10^{-2}$ & 0.022 \\
13.73 & 15.22 & 13.726 & 15.218 & $2.00 \times 10^{-3}$ & $4.25 \times 10^{-2}$ & 0.0406 \\
16.56 & 14.42 & 16.587 & 14.424 & $4.00 \times 10^{-3}$ & $1.57 \times 10^{-1}$ & 0.1572 \\
17.56 & 14.02 & 17.473 & 14.014 & $6.00 \times 10^{-3}$ & $1.23 \times 10^{-1}$ & 0.1232 \\
19.03 & 13.52 & 19.04 & 13.525 & $5.00 \times 10^{-3}$ & $2.37 \times 10^{-1}$ & 0.2368 \\
20.34 & 12.82 & 20.334 & 12.823 & $3.00 \times 10^{-3}$ & $2.21 \times 10^{-1}$ & 0.2188 \\
22.01 & 10.86 & 22.037 & 10.865 & $5.00 \times 10^{-3}$ & $3.59 \times 10^{-1}$ & 0.3726 \\
22.96 & 9.058 & 22.99 & 9.052 & $6.00 \times 10^{-3}$ & $1.01 \times 10^{-2}$ & 0.0512 \\
\hline
\end{tabular}

To validate the approximated pair current and voltage values obtained by Bézier curve method, they are used to reconstruct the V-I and P-I of the $250 \mathrm{~W}$ PEMFC stack. Figure 17a,b present the V-I and P-I characteristic curves of the approximated values by the Bézier curve method along with the experimental data. From the results, it can be observed that the values extracted by the Bézier curve method for the considered $250 \mathrm{~W}$ PEMFC stack fit the experimental data very well, and they are very close.

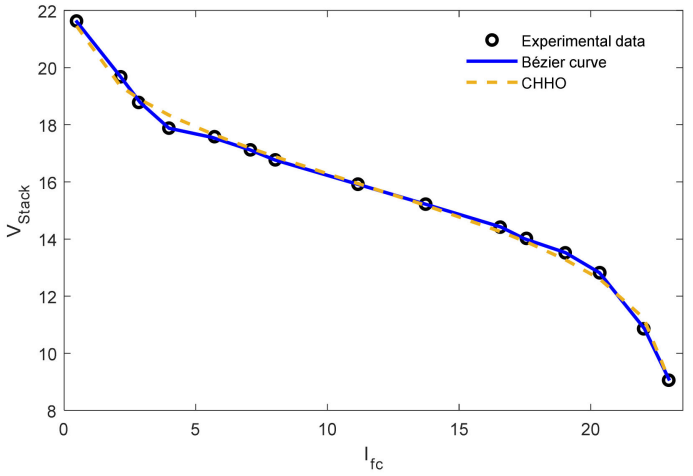

(a)

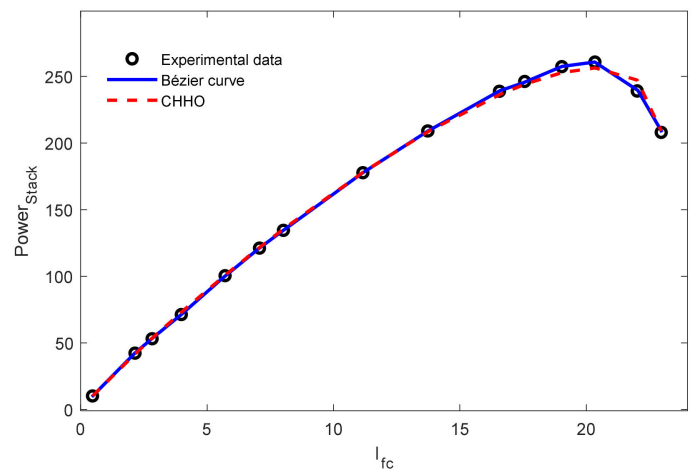

(b)

Figure 17. Comparison of (a) V-I and (b) P-I of 250 W PEMFC stack.

Figure 18 compares the experimental voltage values between the approximated by Bézier curve method and $\mathrm{CHHO}$ algorithm. It is observed that the proposed method provides more accurate values compared to $\mathrm{CHHO}$ algorithm. 


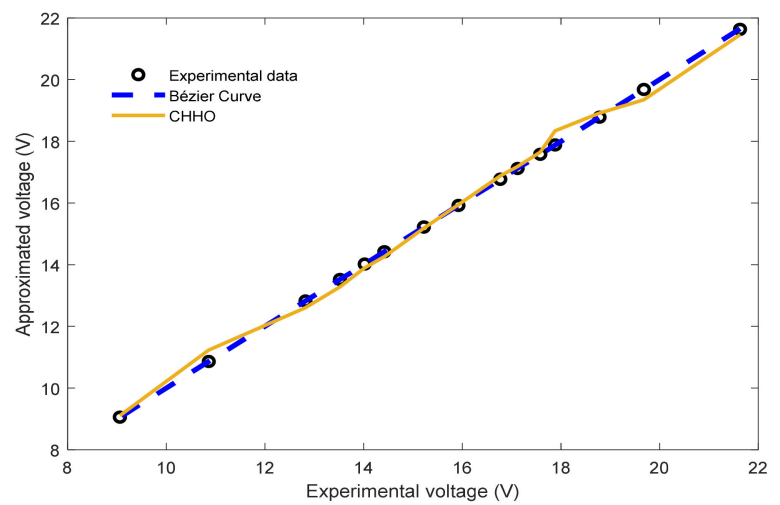

Figure 18. Comparison between experimental and estimated voltage stack of $250 \mathrm{~W}$ PEMFC stack.

The comparison between $\mathrm{CHHO}$ and the proposed algorithm in terms of IAE and RE for each measurement is illustrated in Figure 19a,b. Figure 19 shows that the Bézier curve method has better performance than the other estimation algorithms.

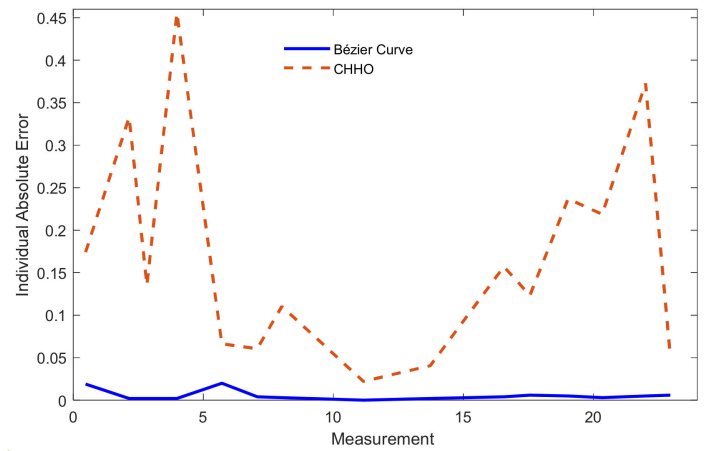

(a)

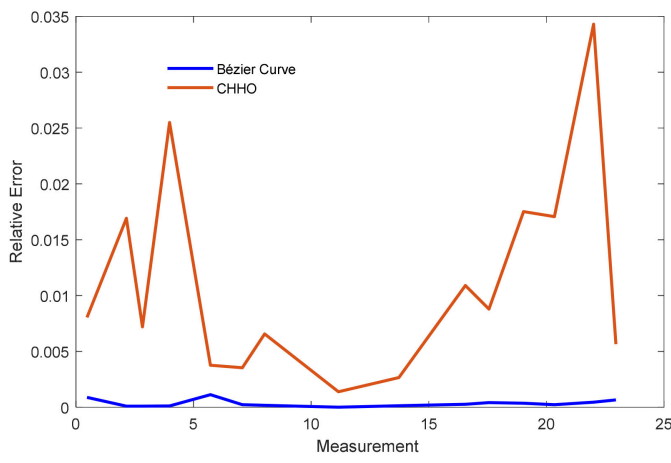

(b)

Figure 19. Comparison of (a) IAE and (b) RE of $250 \mathrm{~W}$ PEMFC stack.

Figure 20 depicted the $A C F$ of the FC $250 \mathrm{~W}$ PEMFC stack. The presented values of the qualified test are in the range of -1 and +1 .

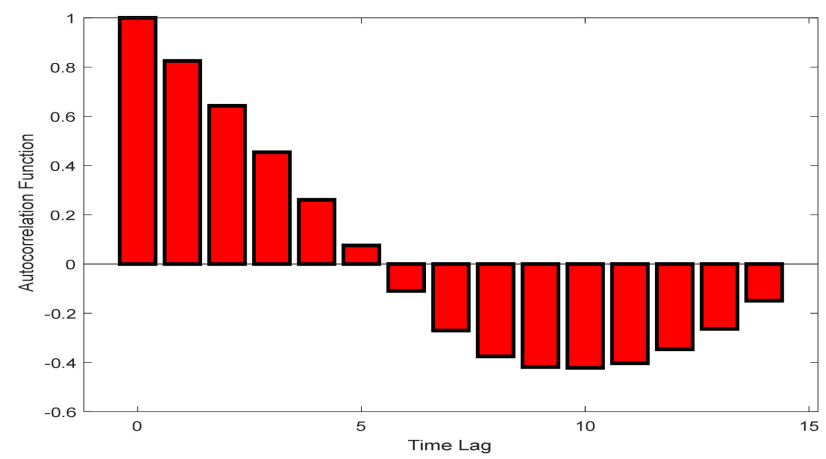

Figure 20. ACF Function of the $250 \mathrm{~W}$ PEMFC stack.

\section{Analysis and Discussion}

The objective of using the statistical criteria is to compare the performance of the calculated data by the Bézier curve method and other algorithms. The RMSE present the standard deviation of the residues of the generated errors. Residuals are a metric of how far away the variables of the regression line are; RMSE is a metric of how these residues are distributed out. In other words, it says how 
distributed the information is in the best match rows. The $M B E$ represents the arithmetic mean of the error and provides information about the long-term performance; the small value is desired as a condition. It can signify whether the model overestimates or underestimates the stack voltage. So, the low values of the statistical measures present the best-estimated model.

Figure 21 illustrates the comparison of RMSE and MBE for the approximated characteristics curves of PEMFC by M/S Ballard Systems, Horizon H-12 W stack, NedStackPS6 PEMFC stack, and 250 W PEMFC stack. It is observed that in all of the considered case studies, the proposed method has the lowest values of RMSE and MBE.

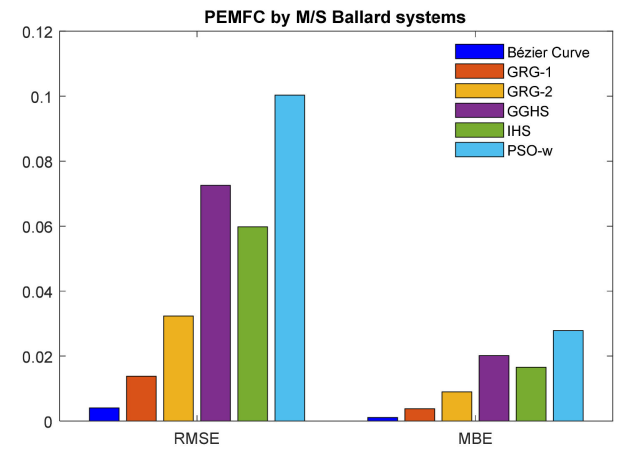

(a)

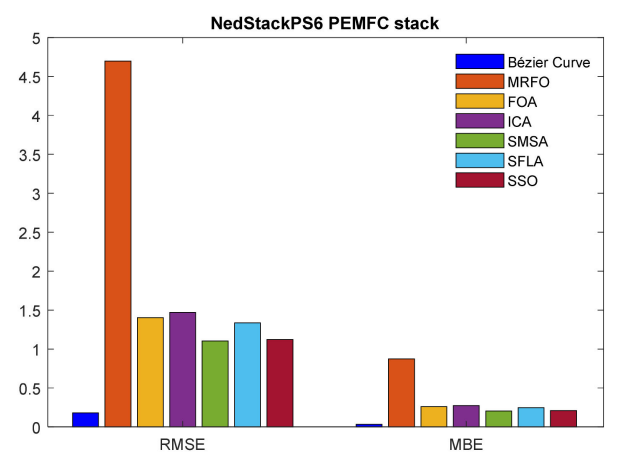

(c)

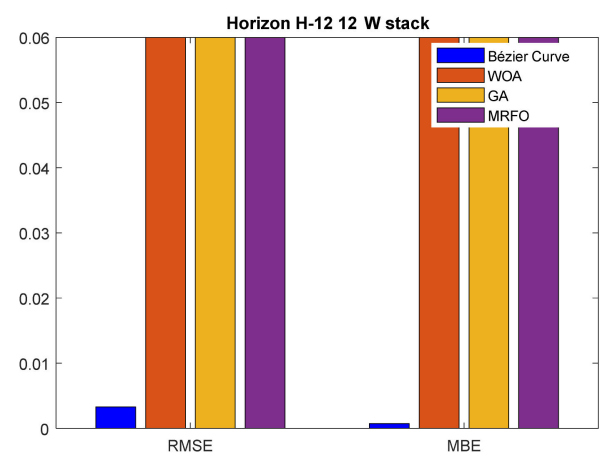

(b)

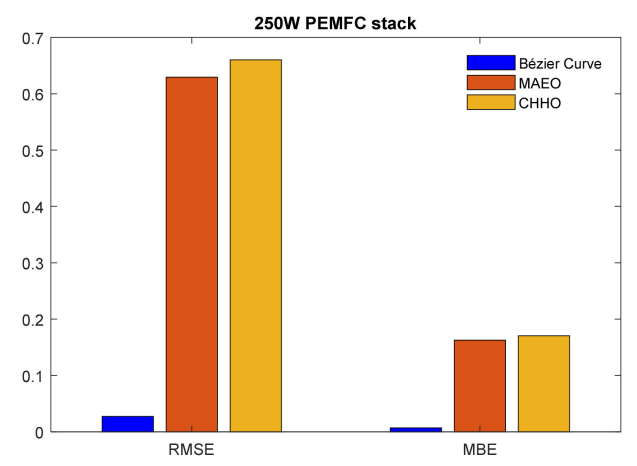

(d)

Figure 21. Comparison of RMSE and MBE of the fuel cells under study, (a) M/S Ballard Systems, (b) Horizon H-12 W stack, (c) NedStack PS6 PEMFC stack, (d) 250 W PEMFC Stack..

In the M/S Ballard Systems the Bézier curve method has the lowest measures' values followed by GRG-1 and GRG-2, while the PSO-w provides the highest measures' values.

For the Horizon H-12 W stack, the Bézier curve method is better than WOA, GA, and MRFO, which have the highest measures' values in RMSE and MBE.

The characteristics curve of NedStackPS6 PEMFC stack has been approximated by the Bézier curve method much better than SSO and SMA, while the highest value is obtained by MRFO, FOA, ICA, and SFLA.

In the last case study, it is observed that the Bézier curve method provides the best values of the curves, much better than MAEO and $\mathrm{CHHO}$ algorithms.

In all case studies, the approximation is very close to the experimental data at low voltage and current. However, in high voltage value and low current, that is a little far. Moreover, the Bézeir curve method outperforms all other algorithms in the four case studies and provides the lowest error measures' values. Further, the approximated values by the Bézier curve method are close to the experimental values in low voltage and high current and also at low current and high voltage. 


\section{Conclusions}

This paper presents the implementation and adaptation of the Bézier curve method to approximate the characteristic curves of four different fuel cells under different conditions. The used experimental data of current and voltage for testing the effectiveness of the proposed technique are based on the results obtained by several algorithms previously developed for parameter extraction and characteristic curves approximation. The voltage-current curve is subdivided using the experimental into segments, and the control points were constructed using the coefficients of the polynomial Bernstein function in the interval of the measured data. The de Casteljau subdivision algorithm is applied to the fuel cell curve to an infinite sequence of control points, which defines a new family of curves. The degree of the Bernstein function depends on the number of the measured data points. The de Casteljau algorithm is used to minimize the distance between the experimental data points and is then approximated to find the best approximation. Further, several statistical metrics are calculated and determined to fit the performance and accuracy of the approximated curves.

The obtained approximated voltage, current, and power are compared with those obtained by recent techniques and methods from the literature. The proposed method provides the lowest value in terms of Individual Absolute Error (IAE), Relative Error (RE), Root Mean Square Error (RMSE), and Mean Bias Error $(M B E)$ compared to other techniques. The comparisons of four cases demonstrate that the Bézier curve method using the adopted statistical error measures provides high performance and accuracy of the approximated current, voltage, and power of the fuel cells. Therefore, the research relevant to the study will then commence focused on analyzing the static and dynamic behavior of the fuel cell model in different conditions. The results of this study create the following opportunities for various potential research:

- Construction of a good fuel cell model device based on the approximated curves;

- Development of a new implicit model.

Because the performance of the results is of significant importance in control management and performance analysis of the fuel cell in hybrid renewable energy systems; the proposed characteristics approximation is a useful feature for monitoring, fault detection and diagnosis of the connected fuel cell.

Author Contributions: Conceptualization, M.L.; methodology, M.L.; software, M.L.; validation, M.L., S.A.-D. and M.M.; formal analysis, M.L.; investigation, M.L., S.A.-D. and M.M.; resources, M.L.; data curation, M.L.; writing-original draft preparation, M.L.; writing-review and editing, M.L., S.A.-D. and M.M.; visualization, M.L., S.A.-D. and M.M.; supervision, M.L.; project administration, M.L.; funding acquisition, M.L. All authors have read and agreed to the published version of the manuscript.

Funding: This research received no external funding.

Acknowledgments: The first author is highly thankful to the Energy Department of University Polytechnic of Milan, Italy, and the Italian Ministry of Foreign Affairs and International Cooperation.

Conflicts of Interest: The authors declare no conflict of interest.

\section{References}

1. Staffell, I.; Scamman, D.; Velazquez-Abad, A.; Balcombe, P.; Dodds, P.E.; Ekins, P.; Shah, N.; Ward, K.R. The role of hydrogen and fuel cells in the global energy system. Energy Environ. Sci. 2019, 12, $463-491$. [CrossRef]

2. Ramadhani, F.; Hussain, M.A.; Mokhlis, H.; Hajimolana, S. Optimization strategies for solid oxide fuel cell (SOFC) application: A literature survey. Renew. Sustain. Energy Rev. 2017, 76, 460-484. [CrossRef]

3. El-Hay, E.A.; El-Hameed, M.A.; El-Fergany, A.A. Optimized parameters of SOFC for steady state and transient simulations using interior search algorithm. Energy 2019, 166, 451-461. [CrossRef]

4. Agwa, M.A.; El-Fergany, A.A.; Sarhan, M.G. Steady-state modeling of fuel cells based on atom search optimizer. Energies 2019, 12, 1884. [CrossRef] 
5. Shen, P.K. PEM fuel cell catalyst layers and MEAs. In PEM Fuel Cell Electrocatalysts and Catalyst Layers: Fundamentals and Applications; Springer: Berlin/Heidelberg, Germany, 2008; pp. 355-380. [CrossRef]

6. Wang, M.; Park, J.H.; Kabir, S.; Neyerlin, K.C.; Kariuki, N.N.; Lv, H.; Stamenkovic, V.R.; Myers, D.J.; Ulsh, M.; Mauger, S.A. Impact of catalyst ink dispersing methodology on fuel cell performance using in-situ x-ray scattering. ACS Appl. Energy Mater. 2019, 2, 6417-6427. [CrossRef]

7. $\mathrm{Xu}, \mathrm{S}$.; Wang, Y.; Wang, Z. Parameter estimation of proton exchange membrane fuel cells using eagle strategy based on JAYA algorithm and nelder-mead simplex method. Energy 2019, 173, 457-467. [CrossRef]

8. Uzunoglu, M.; Alam, M.S. Fuel-cell systems for transportations. In Power Electronics Handbook, 4th ed.; Rashid, M.H., Ed.; Elisevier: Amsterdam, The Netherlands, 2018; pp. 1091-1112. [CrossRef]

9. Chandan, A.; Hattenberger, M.; El-kharouf, A.; Du, S.; Dhir, A.; Self, V.; Pollet, B.G.; Ingram, A.; Bujalski, W. High temperature (HT) polymer electrolyte membrane fuel cells (PEMFC)-a review. J. Power Sources 2013, 231, 264-278. [CrossRef]

10. Chen, F.; Yu, Y.; Gao, Y. Temperature control for proton exchange membrane fuel cell based on current constraint with consideration of limited cooling capacity. Fuel Cells 2017, 17, 662-670. [CrossRef]

11. Shen, X.; Zhang, X.; Lie, T.T.; Li, G. Mathematical modeling and simulation for external electrothermal characteristics of an alkaline water electrolyzer. Int. J. Energy Res. 2018, 42, 3899-3914. [CrossRef]

12. Aouali, F.Z.; Becherif, M.; Ramadan, H.S.; Emziane, M.; Khellaf, A.; Mohammedi, K. Analytical modelling and experimental validation of proton exchange membrane electrolyser for hydrogen production. Int. J. Hydrog. Energy 2017, 42, 1366-1374. [CrossRef]

13. Lee, W.-Y.; Park, G.-G.; Yang, T.-H.; Yoon, Y.-G.; Kim, C.-S. Empirical modeling of polymer electrolyte membrane fuel cell performance using artificial neural networks. Int. J. Hydrog. Energy 2004, 29, 961-966. [CrossRef]

14. El-Fergany, A.A.; Hasanien, H.M.; Agwa, A.M. Semi-empirical PEM fuel cells model using whale optimization algorithm. Energy Convers. Manag. 2019, 201, 112197. [CrossRef]

15. Gao, F.; Blunier, B.; Miraoui, A. Proton Exchange Membrane Fuel Cells Modeling; John Wiley \& Sons, Inc.: Hoboken, NJ, USA, 2013. [CrossRef]

16. Amphlett, C.; Mann, R.F.; Peppley, B.A.; Roberge, P.R.; Rodrigues, A. A model predicting transient responses of proton exchange membrane fuel cells. J. Power Sources 1996, 61, 183-188. [CrossRef]

17. Zhang, L.; Wang, N. Application of coRNA-GA based RBF-NN to model proton exchange membrane fuel cells. Int. J. Hydrog. Energy 2018, 43, 329-340. [CrossRef]

18. Priya, K.; Sathishkumar, K.; Rajasekar, N. A comprehensive review on parameter estimation techniques for proton exchange membrane fuel cell modelling. Renew. Sustain. Energy Rev. 2018, 93, 121-144. [CrossRef]

19. Ritzberger, D.; Striednig, M.; Simon, C.; Hametner, C.; Jakubek, S. Online estimation of the electrochemical impedance of polymer electrolyte membrane fuel cells using broad-band current excitation. J. Power Sources 2018, 405, 150-161. [CrossRef]

20. Taleb, M.A.; Béthoux, O.; Godoy, E. Identification of a PEMFC fractional order model. Int. J. Hydrog. Energy 2017, 42, 1499-1509. [CrossRef]

21. Al-Baghdadi, M.A.R.S. Modelling of proton exchange membrane fuel cell performance based on semi-empirical equations. Renew. Energy 2005, 30, 1587-1599. [CrossRef]

22. Geem, Z.W.; Noh, J.-S. Parameter estimation for a proton exchange membrane fuel cell model using GRG technique. Fuel Cells 2016, 16, 640-645. [CrossRef]

23. Ye, M.; Wang, X.; Xu, Y. Parameter identification for proton exchange membrane fuel cell model using particle swarm optimization. Int. J. Hydrog. Energy 2009, 34, 981-989. [CrossRef]

24. Bouaicha, A.; Allagui, H.; Aglzim, E.-H.; Rouane, A.; Mami, A. Validation of a methodology for determining the PEM fuel cell complex impedance modelling parameters. Int. J. Hydrog. Energy 2017, 42, 12738-12748. [CrossRef]

25. Kandidayeni, M.; Macias, A.; Khalatbarisoltani-Boulon, A.L.; Kelouwani, S. Benchmark of proton exchange membrane fuel cell parameters extraction with metaheuristic optimization algorithms. Energy 2019, 183, 912-925. [CrossRef]

26. Li, J.; Gao, X.; Cui, Y.; Hu, J.; Xu, G.; Zhang, Z. Accurate, efficient and reliable parameter extraction of PEM fuel cells using shuffled multi-simplexes search algorithm. Energy Convers. Manag. 2020, 206, 112501. [CrossRef] 
27. Miao, D.; Chen, W.; Zhao, W.; Demsas, T. Parameter estimation of PEM fuel cells employing the hybrid grey wolf optimization method. Energy 2020, 193, 116616. [CrossRef]

28. Fathy, A.; Elaziz, M.A.; Alharbi, A.G. A novel approach based on hybrid vortex search algorithm and differential evolution for identifying the optimal parameters of PEM fuel cell. Renew. Energy 2020, 146, 1833-1845. [CrossRef]

29. Chen, Y.; Wang, N. Cuckoo search algorithm with explosion operator for modeling proton exchange membrane fuel cells. Int. J. Hydrog. Energy 2019, 44, 3075-3087. [CrossRef]

30. Fawzi, M.; El-Fergany, A.A.; Hasanien, H.M. Effective methodology based on neural network optimizer for extracting model parameters of PEM fuel cells. Int. J. Energy Res. 2019, 43, 8136-8147. [CrossRef]

31. Rao, Y.; Shao, Z.; Ahangarnejad, A.H.; Gholamalizadeh, E.; Sobhani, B. Shark smell optimizer applied to identify the optimal parameters of the proton exchange membrane fuel cell model. Energy Convers. Manag. 2019, 182, 1-8. [CrossRef]

32. El-Fergany, A.A. Extracting optimal parameters of PEM fuel cells using salp swarm optimizer. Renew. Energy 2018, 119, 641-648. [CrossRef]

33. El-Fergany, A.A. Electrical characterisation of proton exchange membrane fuel cells stack using grasshopper optimizer. IET Renew. Power Gener. 2018, 12, 9-17. [CrossRef]

34. Ali, M.; El-Hameed, M.A.; Farahat, M.A. Effective parameters' identification for polymer electrolyte membrane fuel cell models using grey wolf optimizer. Renew. Energy 2017, 111, 455-462. [CrossRef]

35. Turgut, O.E.; Coban, M.T. Optimal proton exchange membrane fuel cell modelling based on hybrid Teaching Learning Based Optimization-Differential Evolution algorithm. Ain Shams Eng. J. 2016, 7, 347-360. [CrossRef]

36. Sun, Z.; Wang, N.; Bi, Y.D. Srinivasan, parameter identification of PEMFC model based on hybrid adaptive differential evolution algorithm. Energy 2015, 90, 1334-1341. [CrossRef]

37. Restrepo, C.; Konjedic, T.; Garces, A.; Calvente, J.; Giral, R. Identification of a proton-exchange membrane fuel cell's model parameters by means of an evolution strategy. IEEE Trans. Ind. Inform. 2015, 11, 548-559. [CrossRef]

38. Selem, S.I.; Hasanien, H.M.; El-Fergany, A.A. Parameters extraction of PEMFC's model using manta rays foraging optimizer. Int. J. Energy Res. 2020, 44, 1-12. [CrossRef]

39. Gong, W.; Yan, X.; Liu, X.; Cai, Z. Parameter extraction of different fuel cell models with transferred adaptive differential evolution. Energy 2015, 8, 139-151. [CrossRef]

40. Cheng, J.; Zhang, G. Parameter fitting of PEMFC models based on adaptive differential evolution. Int. J. Electr. Power Energy Syst. 2014, 62, 189-198. [CrossRef]

41. Askarzadeh, A.; Rezazadeh, A. An innovative global harmony search algorithm for parameter identification of a PEM fuel cell model. IEEE Trans. Ind. Electron. 2012, 59, 3473-3480. [CrossRef]

42. Mohamed, N.; Majid, A.A.; Piah, A.R.M. Data fitting by G1 rational cubic Bézier curves using harmony search. Egypt. Inform. J. 2015, 16, 175-185. [CrossRef]

43. Kawabata, K.; Ma, L.; Xue, J.; Zhu, C.; Zheng, N. A path generation for automated vehicle based on Bezier curve and via-points. Rob. Auton. Syst. 2015, 74, 243-252. [CrossRef]

44. Huo, M.; Mengali, G.; Quarta, A.A.; Qi, N. Electric sail trajectory design with Bezier curve-based shaping approach. Aerosp. Sci. Technol. 2019, 88, 126-135. [CrossRef]

45. Fürst, Y.; Brandt, S.; Kriegel, M. Thermal modelling of three-way mixing valves using Bézier curves for parameter estimation applications. J. Process. Control. 2020, 90, 56-62. [CrossRef]

46. Susam, S.O.; Hudaverdi, U.B. A goodness-of-fit test based on Bézier curve estimation of Kendall distribution. J. Stat. Comput. Simul. 2020, 90, 1194-1215. [CrossRef]

47. Ahn, Y.J. Circle approximation by G 2 Bézier curves of degree $\mathrm{n}$ with $2 \mathrm{n}-1$ extreme points. J. Comput. Appl. Math. 2019, 358, 20-28. [CrossRef]

48. Liu, Y.; Dong, X.C. Approximation of conic section by quartic Bézier curve with endpoints continuity condition. Appl. Math. 2017, 32, 1-13. [CrossRef]

49. Menesy, A.S.; Sultan, H.M.; Korashy, A.; Banakhr, F.A.; Ashmawy, M.G.; Kamel, S. Effective parameter extraction of different polymer electrolyte membrane fuel cell stack models using a modified artificial ecosystem optimization algorithm. IEEE Access 2020, 8, 31892-31909. [CrossRef]

50. Askarzadeh, A.; Rezazadeh, A. A grouping-based global harmony search algorithm for modeling of proton exchange membrane fuel cell. Int. J. Hydrogen Energy 2011, 36, 5047-5053. [CrossRef] 
51. Menesy, A.S.; Sultan, H.M.; Selim, A.; Ashmawy, M.G.; Kamel, S. Developing and applying chaotic harris hawks optimization technique for extracting parameters of several proton exchange membrane fuel cell stacks. IEEE Access 2020, 8, 1146-1159. [CrossRef]

52. Outeiro, M.T.; Chibante, R.; Carvalho, A.S.; de Almeida, A.T. A new parameter extraction method for accurate modeling of PEM fuel cells. Int. J. Energy Res. 2009, 33, 978-988. [CrossRef]

53. Huang, X.; Zhang, Z.; Jiang, J. Fuel Cell Technology for Distributed Generation: An Overview; IEEE: Piscataway, NJ, USA, 2006; pp. 1613-1618. [CrossRef]

54. Morin, G.; Goldman, R. A subdivision scheme for Poisson curves and surfaces. Comput. Aided Geom. Des. 2000, 17, 813-833. [CrossRef]

55. Louzazni, M.; Khouya, A.; Amechnoue, K.; Mussetta, M.; Crăciunescu, A. Comparison and evaluation of statistical criteria in the solar cell and photovoltaic module parameters' extraction. Int. J. Ambient Energy 2018, 41, 1-13. [CrossRef]

56. Khandakar, A.; Chowdhury, M.E.H.; Kazi, M.K.; Benhmed, K.; Touati, F.; Al-Hitmi, M.; Gonzales, A.S.P.J. Machine learning based photovoltaics (PV) power prediction using different environmental parameters of Qatar. Energies 2019, 12, 2782. [CrossRef]

57. Stacks, H.-S.F.C. H-12 PEM Fuel Cell 12W-Horizon Educational. Available online: https://www. horizoneducational.com/advancedproducts/h-12-pem-fuel-cell-12w/ (accessed on 12 September 2020).

(C) 2020 by the authors. Licensee MDPI, Basel, Switzerland. This article is an open access article distributed under the terms and conditions of the Creative Commons Attribution (CC BY) license (http://creativecommons.org/licenses/by/4.0/). 